\title{
Government Spending and Durable Goods
}

\author{
Christoph E. Boehm
}

\author{
CESIFO WORKING PAPER NO. 6244 \\ CATEgory 6: Fiscal Policy, Macroeconomics AND GrowTH \\ DECEMBER 2016
}

An electronic version of the paper may be downloaded

- from the SSRN website:

- from the RePEc website:

- from the CESifo website: wWw.SSRN.com

Www.RePEc.org

www.CESifo-group.org/wp 


\title{
Government Spending and Durable Goods
}

\begin{abstract}
This paper shows that the fiscal multiplier for purchases of durable and investment goods is very small - much smaller than the multiplier for nondurable goods. Standard models predict small durables multipliers because private sector purchases of durable goods are highly intertemporally substitutable and therefore easily crowded out. Empirical estimates based on U.S. data confirm this result. In aggregate time series data output rises by about 50 cents less if the government purchases $1 \$$ of durable rather than nondurable goods. At the industry level, spending on durable goods leads to smaller sectoral expansions than spending on nondurable goods. The findings of this paper suggest that infrastructure spending which is frequently part of fiscal stimulus packages is relatively ineffective at raising aggregate demand.
\end{abstract}

JEL-Codes: E210, E320, E620, E630.

Keywords: durable goods, fiscal policy, government spending, fiscal multiplier.

\author{
Christoph E. Boehm \\ U.T. Austin and Princeton University \\ Department of Economics \\ USA - Princeton, NJ 08540 \\ cboehm@princeton.edu
}

October 10, 2016

This paper formerly circulated under the title Fiscal Policy and Durable Goods. I would like to thank Chris House, Matthew Shapiro, Stefan Nagel, Joshua Hausman, and Edward Ionides for valuable comments, suggestions, and support. I also thank Saroj Bhattarai, Matias Cattaneo, Charlie Brown, Aaron Flaaen, Jordi Gali, Simon Gilchrist, Jim Hamilton, Miles Kimball, David Lagakos, Ben Meiselman, Emi Nakamura, Pablo Ottonello, Nitya Pandalai-Nayar, Valerie Ramey, Dimitrije Ruzic, Richard Ryan, Jeff Smith, Isaac Sorkin, Johannes Wieland, and Justin Wolfers for helpful conversations as well as the participants of the seminars at Michigan, UIUC, the Bank of Canada, the Federal Reserve Board, CREI, Warwick, Cambridge, INSEAD, IIES, the Boston Fed, Notre Dame, Columbia, UT Austin, the San Francisco Fed, UCSD, Oregon, the EGSC in St. Louis, the Fall 2015 Midwest Macro Meeting in Rochester, and the 85th Annual Meetings of Southern Economic Association. 


\section{Introduction}

When the government raises spending by one dollar, GDP changes by an amount that is generally not one dollar. The difference arises from the fact that households and firms change their behavior when the government intervenes - a phenomenon known as crowding in or out. It is well understood that the private sector response depends on whether the fiscal intervention is temporary or permanent (Baxter and King 1993). Recent research has suggested that the response can also depend on whether the economy's factors of production are underutilized (e.g. Michaillat 2014) and whether the central bank accommodates the change in spending (e.g. Christiano, Eichenbaum, and Rebelo 2011, Woodford 2011, and Rendahl 2014).

In this paper I argue that the composition of government spending matters for the size of the fiscal multiplier. I show that in a two sector model purchases of durable goods have a much smaller multiplier than purchases of nondurable goods. I then estimate multipliers separately for spending in durables and nondurables industries. While, on average, a dollar of spending on durable goods raises industry gross output by less than 30 cents, gross output rises more than one-for-one if the government buys nondurable goods. These findings suggest that infrastructure spending has very small affects on aggregate demand.

The demand for nondurable goods differs fundamentally from the demand for new durables. Whereas nondurable goods and services are immediately consumed, durable goods such as cars, appliances or structures have service lives of many years. If the price of a durable good rises temporarily, households can rely on the existing stock and postpone new purchases until prices revert to lower levels. All else equal, a longer service life leads to a greater intertemporal substitutability of purchases.

Intertemporal substitutability is key for the fiscal multiplier because it determines how much private sector spending is crowded out. If the government temporarily raises spending and drives up prices, households delay new purchases until the fiscal expansion ends. The higher the intertemporal elasticity of substitution the larger the degree of crowding out. It follows that multipliers for durable goods with high intertemporal elasticities of substitution are smaller than multipliers for nondurable goods with low intertemporal elasticities of substitution.

In standard models the difference between durable and nondurable multipliers is large. When the service life is calibrated to realistic levels, the durables multiplier is often less than one third of 
the nondurables multiplier. I also show that the durables multiplier approaches zero as the service life of the durable good becomes large. The prediction that durables multipliers are smaller than nondurables multipliers holds for both New Keynesian and neoclassical models.

Research by Woodford (2011), Christiano, Eichenbaum, and Rebelo (2011), and Farhi and Werning (2012), among others, has emphasized that the size of the fiscal multiplier is highly sensitive to the monetary policy response. Interestingly, the durables multiplier often depends less on monetary policy than the nondurables multiplier. Because purchases of durables crowd out private sector spending, equilibrium quantities and prices move little relative to the case in which the government purchases nondurable goods. With output and prices barely changed, the monetary policy response matters less. In the special case in which the service life of durables becomes large, the allocation is independent of monetary policy for a large class of rules.

I estimate fiscal multipliers separately for durable and nondurable goods, beginning with evidence based on U.S. national accounts data. In simple regressions which take U.S. military spending as exogenous (Hall 2009 and Barro and Redlick 2011) the nondurables multiplier exceeds the durables multiplier by about 0.5. Consistent with theory, government purchases of durable goods are associated with declines in private sector investment and purchases of durable goods.

I subsequently turn to an analysis at the industry level. In particular, I assemble a new dataset from the NBER-CES Manufacturing Industry Database and two databases covering the universe of U.S. military prime contracts. The merged dataset contains industry-level outcomes such as gross output, value added, and employment together with military spending on goods in each 4-digit SIC manufacturing industry.

As predicted by the theory, industries that produce durable goods respond much less to fiscal expansions than industries that produce nondurable goods. Using an identification strategy closely related to Ramey and Shapiro (1998), Nekarda and Ramey (2011), and Nakamura and Steinsson (2014), I first estimate impulse response functions. I then construct industry-level multipliers from the estimated impulse response functions separately for durable and nondurable goods. The multipliers for all five measures of economic activity I consider-gross output, value added, cost of materials, energy expenditures, and employment - are smaller if spending takes place in durable goods industries.

This paper is related to a large literature on the effects of government spending. Hall (2009) 
shows in a simple static model with a single nondurable good that the fiscal multiplier is decreasing in the intertemporal elasticity of substitution. In his model the multiplier tends to zero as the intertemporal elasticity of substitution approaches infinity. I show that the same result holds approximately for short-run multipliers of long-lived durable goods. Consistent with this result, House (2009) argues that among the options that households face in response to greater government spending, reducing investment is more attractive than reducing consumption or raising the supply of labor.

Most of the literature on fiscal multipliers does not distinguish between purchases of durable and nondurable goods. Exceptions include Perotti (2004) and Pappa (2009ba) who study the effects of government consumption and investment using structural vector autoregressions. Their findings are broadly consistent with the hypothesis that government consumption is associated with greater multipliers than government investment. ${ }^{1}$ Paying particular attention to anticipation effects and timing Leduc and Wilson (2013) study the effects of public infrastructure spending. They find a very large short-term multiplier in recessions and an insignificant short-term multiplier in expansions. ${ }^{2}$

A number of studies have suggested that the fiscal multiplier is larger during economic downturns than in times of peak economic activity (e.g. Auerbach and Gorodnichenko 2012, 2013, Bachmann and Sims 2012, and Michaillat 2014). ${ }^{3}$ By far the most commonly cited reason for such state dependence is that the presence of slack: If factors of production are underutilized there is less crowding out of private sector spending, leading to a larger fiscal multiplier. Since durable goods industries exhibit high volatility over the business cycle, one may conjecture that the state dependence hypothesis applies particularly to spending on durable goods. Yet, when I allow for state dependence in the estimation of the durable goods multiplier, I find no indication for greater effectiveness when spending occurs in times of economic slack. ${ }^{4}$

Although I cast my analysis largely in terms of consumer durables, I note that the demand for investment goods such as machines, ships or structures is also highly elastic (House and Shapiro

\footnotetext{
${ }^{1}$ See in particular tables 4 to 6 in Perotti (2004), the "typical" state-level employment responses in figure 3 in Pappa (2009b) and table 1 in Pappa (2009a).

${ }^{2}$ Other papers that distinguish different government interventions include Finn (1998), and Pereira (2000). Aschauer (1989) studies the effect of public expenditure on productivity.

${ }^{3}$ The evidence on state dependence of fiscal multipliers is not uncontroversial. Owyang, Ramey, and Zubairy (2013) find that the multiplier in recessions is large in Canada, but not in the U.S.

${ }^{4}$ In fact, Berger and Vavra (2014) argue that the durable goods fiscal multiplier may be smaller in recessions than during expansions.
} 
2008). In the empirical part of this paper, I will refer to all long-lived goods as durable goods, regardless of whether they are consumer durables or investment goods. Because services are immediately consumed, they are best understood as nondurable goods in the context of this paper.

The remainder of the paper is structured as follows. In the next section, I lay out a simple theory predicting that the multiplier for durables is small relative to that of nondurable goods. I then turn to the empirical analysis in Section 3. In Section 4 I analyze an extension of the model in which the interest rate is pinned at the zero lower bound. Section 5 concludes.

\section{Theoretical analysis}

I next present a New Keynesian two sector model to study the effectiveness of government spending on durable and nondurable goods. After describing the model, I demonstrate that the intertemporal elasticity of substitution of durable goods purchases is much larger than that of nondurable goods purchases. I then show that their high intertemporal substitutability renders the durable goods multiplier small.

\subsection{Model description}

The model is designed to mirror the empirical setting I face below: There is a large number of (4digit SIC) industries. Some of these industries produce durable goods, others produce nondurable goods. I am interested in the effect on GDP when the government increases spending in a typical durable or a typical nondurable goods industry.

To keep the framework tractable, I only model two sectors, a small sector $X$ and a large sector $Z$. The small sector represents a typical 4-digit SIC manufacturing industry that is subjected to a government spending shock. Depending on the choice of the depreciation rate $\delta_{D}$, the small sector

produces either durable or nondurable goods for final consumption. The large sector $Z$ represents the aggregate of all remaining industries. It produces goods which can alternately be used for final nondurable consumption $C$, for investment into capital of the two sectors, $I_{Z}$ and $I_{X}$, or for intermediate goods $M_{X}$ used in the production of good $X$. For simplicity, there is no government spending on goods in the $Z$ sector. Notice that $Z$ is a hybrid sector, producing both nondurable goods $\left(C\right.$ and $\left.M_{X}\right)$ and durable investment goods $\left(I_{Z}\right.$ and $\left.I_{X}\right)$. 


\subsubsection{Representative household}

The representative household maximizes life-time utility

$$
\mathbb{E}_{0} \sum_{t=0}^{\infty} \beta^{t}\left[u\left(C_{t}, D_{H, t}\right)+\Gamma_{t}-v\left(N_{X, t}, N_{Z, t}\right)\right]
$$

subject to the nominal budget constraint

$$
\begin{aligned}
P_{X, t} X_{H, t}+P_{Z, t} & \left(C_{t}+I_{X, t}+I_{Z, t}\right)+B_{t}+T_{t} \\
& =W_{X, t} N_{X, t}+W_{Z, t} N_{Z, t}+R_{X, t} K_{X, t-1}+R_{Z, t} K_{Z, t-1}+B_{t-1}\left(1+i_{t-1}\right)+\Pi_{t}
\end{aligned}
$$

the accumulation equations

$$
D_{H, t}=X_{H, t}+\left(1-\delta_{D}\right) D_{H, t-1}, \quad K_{j, t}=I_{j, t}+\left(1-\delta_{K}\right) K_{j, t-1}, j \in\{Z, X\},
$$

and a no-Ponzi game condition.

Utility is derived from three components. The first component, $u$, reflects the benefit derived from the consumption of the nondurable good $C_{t}$ and the good $D_{H, t}$. When $\delta_{D}=1, D_{H, t}=X_{H, t}$ is a nondurable good. For $\delta_{D}<1, D_{H, t}$ is the household's stock of durable goods, while $X_{H, t}$ are new purchases. The second component, $\Gamma_{t}$, represents the household's utility derived from government purchases. I assume that $\Gamma$ enters additively separable so that government spending is neither a substitute nor a complement for private sector spending. Finally, the third term is the household's disutility from supplying labor to the two sectors. Letting subscripts denote partial derivatives, I assume that 1) $\left.\left.u_{C}, u_{D}, v_{X}, v_{Z}>0,2\right) u_{C C}, u_{D D}<0,3\right) v_{X X}, v_{Z Z}>0$, and 4) that Inada-type conditions hold.

The remaining notation is chosen as follows. $P_{X, t}$ and $P_{Z, t}$ denote the prices in the $X$ and the $Z$ sector. Wages are analogously denoted by $W_{X, t}$ and $W_{Z, t}$. Each sector has its own capital stock $K_{X, t}$ and $K_{Z, t}$, earning rental rates $R_{X, t}$ and $R_{Z, t}$. The representative household can hold risk-free nominal bonds, $B_{t}$, paying interest rate $i_{t}$. $\Pi_{t}$ are profits and $T_{t}$ is a lump-sum tax. 


\subsubsection{Firms}

Both sectors have a representative aggregating firm and a unit continuum of differentiated firms. The aggregating firms assemble the differentiated varieties into CES bundles

$$
X_{t}=\left[\int_{0}^{1} x_{t}(s)^{\frac{\varepsilon-1}{\varepsilon}} d s\right]^{\frac{\varepsilon}{\varepsilon-1}}, \quad Z_{t}=\left[\int_{0}^{1} z_{t}(s)^{\frac{\varepsilon-1}{\varepsilon}} d s\right]^{\frac{\varepsilon}{\varepsilon-1}}
$$

Optimal behavior in competitive markets implies the demand functions

$$
x_{t}(s)=X_{t}\left(\frac{p_{x, t}(s)}{P_{X, t}}\right)^{-\varepsilon}, \quad z_{t}(s)=Z_{t}\left(\frac{p_{z, t}(s)}{P_{Z, t}}\right)^{-\varepsilon}
$$

where $p_{x, t}(s)$ and $p_{z, t}(s)$ denote the prices of a generic variety $s$ in each sector and $P_{X, t}$ and $P_{Z, t}$ are given by

$$
P_{X, t}=\left(\int_{0}^{1}\left(p_{x, t}(s)\right)^{1-\varepsilon} d s\right)^{\frac{1}{1-\varepsilon}}, \quad P_{Z, t}=\left(\int_{0}^{1}\left(p_{z, t}(s)\right)^{1-\varepsilon} d s\right)^{\frac{1}{1-\varepsilon}} .
$$

A differentiated firm in sector $X$ produces variety $s$ using production function

$$
x_{t}(s)=\left[\left(k_{x, t}(s)\right)^{\alpha}\left(n_{x, t}(s)\right)^{1-\alpha}\right]^{\chi}\left[m_{x, t}(s)\right]^{1-\chi} .
$$

The firm rents capital $k_{x, t}(s)$ at rate $R_{X, t}$ and employs labor $n_{x, t}(s)$ at wage $W_{X, t}$. Additionally, production requires an intermediate $m_{x, t}(s)$ from the large sector. Parameter $\chi$ is the cost share of capital and labor and $(1-\chi)$ is that of intermediates. Cost minimization in competitive factor markets yields the firm's conditional factor demand functions and an expression for its marginal costs $M C_{X, t}$.

Firms set prices as in Calvo (1983). Let $\theta_{X}$ denote the probability that a firm in sector $X$ cannot adjust its price. Let further $\lambda$ denote the Lagrange multiplier on the budget constraint (1). Then the monopolistically competitive firm chooses the reset price $p_{X, t}^{*}$ to maximize objective

$$
\mathbb{E}_{t} \sum_{j=0}^{\infty}\left(\theta_{X} \beta\right)^{j} \frac{\lambda_{t+j}}{\lambda_{t}}\left[p_{X, t}^{*} x_{t+j}-M C_{X, t+j} x_{t+j}\right]
$$

subject to the sequence of demand functions (the first equation in 4) and its marginal costs $M C_{X, t+j}$. 
The optimal reset price is

$$
p_{X, t}^{*}=\frac{\varepsilon}{\varepsilon-1} \frac{\mathbb{E}_{t} \sum_{j=0}^{\infty}\left(\theta_{X} \beta\right)^{j} \lambda_{t+j} X_{t+j}\left(P_{X, t+j}\right)^{\varepsilon} M C_{X, t+j}}{\mathbb{E}_{t} \sum_{j=0}^{\infty}\left(\theta_{X} \beta\right)^{j} \lambda_{t+j} X_{t+j}\left(P_{X, t+j}\right)^{\varepsilon}} .
$$

Monopolistic competitors in the large sector behave similarly. The only difference is that they do not require an intermediate input. Their production function is simply $z_{t}(s)=\left(k_{z, t}(s)\right)^{\alpha}\left(n_{z, t}(s)\right)^{1-\alpha}$, and capital and labor are paid the rental rate $R_{Z, t}$ and the wage $W_{Z, t}$. Price rigidity in sector $Z$ is parameterized by $\theta_{Z}$. Notice that I assume that productivity in both sectors is unaffected by government spending.

\subsubsection{Market clearing, government, accounting, and monetary policy}

Market clearing in sectors $Z$ and $X$ requires

$$
Z_{t}=C_{t}+I_{X, t}+I_{Z, t}+M_{X, t} \text { and } X_{t}=X_{H, t}+X_{G, t}
$$

where $M_{X, t}=\int_{0}^{1} m_{x, t}(s) d s$ is the total of intermediates demanded by the $X$ sector and $X_{G}$ is government spending on good $X$. The labor and capital market clearing conditions are given by

$$
N_{X, t}=\int_{0}^{1} n_{x, t}(s) d s, \quad N_{Z, t}=\int_{0}^{1} n_{z, t}(s) d s
$$

and

$$
K_{X, t-1}=\int_{0}^{1} k_{x, t}(s) d s, \quad K_{Z, t-1}=\int_{0}^{1} k_{z, t}(s) d s .
$$

Since the economy is closed and the government always balances its budget $\left(T_{t}=P_{X, t} X_{G, t}\right)$, bonds are in zero net supply, $B_{t}=0 .^{5} \mathrm{I}$ assume that government purchases in sector $X$ follow the $\operatorname{AR}(1)$ process

$$
X_{G, t}=\left(1-\varrho_{X}\right) X_{G}+\varrho_{X} X_{G, t-1}+\varepsilon_{G, t} .
$$

Variables without time subscripts, such as $X_{G}$, denote steady state values.

GDP in constant prices is

$$
Y_{t}=P_{X} X_{t}-P_{Z} M_{X, t}+P_{Z} Z_{t}
$$

\footnotetext{
${ }^{5}$ Since Ricardian equivalence holds in this model, the balanced budget assumption is not restrictive.
} 
The GDP deflator and inflation are then

$$
P_{t}=\frac{P_{X, t} X_{t}+P_{Z, t} Z_{t}-P_{Z, t} M_{X, t}}{P_{X} X_{t}+P_{Z} Z_{t}-P_{Z} M_{X, t}} \text { and } \pi_{t}=\left(P_{t}-P_{t-1}\right) / P_{t-1}
$$

I initially assume that the monetary authority follows a fairly general rule of the form

$$
i_{t}=\iota\left(\left\{i_{t-s-1}, P_{t-s}, P_{X, t-s}, P_{Z, t-s}, Y_{t-s}, X_{t-s}, Z_{t-s}\right\}_{s=0}^{\infty}\right)
$$

where $\iota$ is any function of the given arguments. This completes the description of the model. I summarize all equations in Appendix A.1.

\subsection{The demand for durable and nondurable goods}

I next compare the demand for durable and nondurable goods. I first demonstrate that the low intertemporal elasticity of substitution of nondurables implies a very inelastic demand curve at a given point in time. I then show that the demand for durables has a much higher demand elasticity, reflecting the high substitutability of durables purchases over time.

Denote by $\gamma$ the Lagrange multiplier on the accumulation equation of durable goods (the first equation in 2) and recall that $\lambda$ is the Lagrange multiplier on the nominal budget constraint (1). Hence, $\gamma$ is the shadow value of good $X$, expressed in utils, and $\lambda$ represents the marginal utility of one dollar. Optimal behavior of the representative household (section 2.1.1) then implies that

$$
\gamma_{t}=u_{D}\left(C_{t}, D_{H, t}\right)+\beta\left(1-\delta_{D}\right) \mathbb{E}_{t}\left[\gamma_{t+1}\right]
$$

and

$$
P_{X, t}=\lambda_{t}^{-1} \gamma_{t}
$$

As equation (14) shows, the shadow value of good $X$ equals a flow component $u_{D}$ plus a continuation value. Solving this equation forward and combining the result with (15) yields

$$
P_{X, t}=\lambda_{t}^{-1} \mathbb{E}_{t} \sum_{s=0}^{\infty}\left[\beta\left(1-\delta_{D}\right)\right]^{s} u_{D}\left(C_{t+s}, D_{H, t+s}\right)
$$

This expression can be interpreted as the household's (inverse) demand function for $X$. It is helpful 
to first discuss the special case in which $\delta_{D}=1$.

\subsubsection{Nondurable goods}

If $\delta_{D}=1$, the small sector produces a nondurable good, $D_{H, t}=X_{H, t}$, and equation (16) reduces to the familiar expression

$$
P_{X, t}=\lambda_{t}^{-1} u_{D}\left(C_{t}, X_{H, t}\right)
$$

Next, define the intertemporal elasticity of substitution of $D_{H}$ as $\sigma_{D}=-\frac{u_{D}\left(C, D_{H}\right)}{D_{H} u_{D D}\left(C, D_{H}\right)}$. The linear approximation of equation (17) then implies that, ceteris paribus, a one percent change in $X_{H, t}$ reduces $P_{X, t}$ by $\sigma_{D}^{-1}$ percent. Hence, a low intertemporal elasticity of substitution $\sigma_{D}$ implies that the demand curve for nondurable goods is inelastic.

Estimates of elasticity $\sigma_{D}$ vary and are somewhat controversial. A recent study by Cashin and Unayama (2012) which explicitly distinguishes nondurable from storable and durable goods estimates a value 0.21 , similar to Hall's 1988 estimates. Such a low value suggests that consumption barely responds to changes in intertemporal prices or, equivalently, that the demand curve for nondurables is very steep. Even if $\sigma_{D}$ is set to unity, a popular choice in the literature, the demand for nondurables is much less elastic than that for durables.

\subsubsection{Durable goods}

Due to the dynamic nature of the model, an analogous elasticity for durable goods $\left(\delta_{D}<1\right)$ is difficult to obtain. Instead, I will argue on the basis of equation (16) that in a limiting case the shadow value of the durable good $\gamma_{t}$ is approximately constant. If $\gamma_{t}$ is constant, the demand for $X_{t}$ is perfectly elastic (see equation 15). The limiting approximation assumes that $\beta$ approaches unity, $\delta_{D}$ approaches zero and that all disturbances are short-lived - a reasonable assumption for temporary fiscal expansions. Of course, many durable goods do not have depreciation rates near zero. For instance, the Bureau of Economic Analysis (BEA) estimates the service life of furniture at 14 years. ${ }^{6}$ Yet, the approximation provides the correct intuition that the demand elasticity rises with greater durability and it remains quite accurate for realistic calibrations of $\delta_{D}$. I provide details on the numerical accuracy of this approximation below.

To see why $\gamma_{t}$ is approximately constant for long-lived durables, first notice that the consumer

\footnotetext{
${ }^{6}$ For the BEA's estimates of service lives, see Bureau of Economic Analysis (undated).
} 
derives utility from the stock of the durable good $D_{H, t}$, not current purchases $X_{H, t}$. Because durables with long service lives have large stock to flow ratios (in steady state $D_{H} / X_{H}=1 / \delta_{D}$ ), even large changes in $X_{H, t}$ cause only relatively small percentage changes in $D_{H, t}$.

Second, if the household is sufficiently patient ( $\beta$ close to unity) and the durable long-lived $\left(\delta_{D}\right.$ close to zero), the shadow value $\gamma_{t}$ depends on utility flows far in the future. In stationary environments with short-lived shocks these future terms are barely affected since the economy quickly reverts back to its steady state. Any changes to the first few terms in the sum of equation (16) are dwarfed by the future terms which remain approximately unchanged. Hence, as $\beta$ approaches unity and $\delta_{D}$ approaches zero, the shadow value $\gamma_{t}$ becomes unresponsive to temporary shocks and the demand for $X_{H, t}$ perfectly elastic. ${ }^{7}$

Intuitively, the household smoothes consumption of both nondurable and durable goods. But since utility is derived from the stock the consumer is willing to tolerate much larger variation in durables purchases than in nondurables purchases. It is optimal to purchase durables only at favorable prices and to draw down the stock whenever prices are temporarily high. Mankiw (1985), Adda and Cooper (2000), Erceg and Levin (2006), Mian and Sufi (2012) and Hausman (2015) all provide evidence for large intertemporal substitutability of durable goods purchases.

\subsection{Implications for fiscal policy}

The demand elasticity is crucial for the size of the fiscal multiplier because it determines the degree to which private sector spending is crowded out. The basic intuition can then be illustrated in a demand and supply diagram.

Suppose the government raises spending and shifts out the demand curve. If the supply curve is upward-sloping, the resulting price increase reduces private sector spending. Greater demand elasticities lead to greater crowding-out. In the limiting case with horizontal demand curve, all private sector spending is crowded out and the fiscal expansion has no effect. Figure 1 illustrates the effect of government spending in a sector with inelastic demand (Panel A) and elastic demand (Panel B). The supply curve and the fiscal expansion are the same in both sectors.

Before turning to a more formal analysis of fiscal policy I briefly define sector-level analogues of the aggregate fiscal multiplier $\mathrm{d} Y / \mathrm{d} G$. These sectoral multipliers help link the theoretical analysis

\footnotetext{
${ }^{7} \mathrm{~A}$ similar argument is made in Barsky, House, and Kimball (2007).
} 
Figure 1: Crowding out of private sector spending.
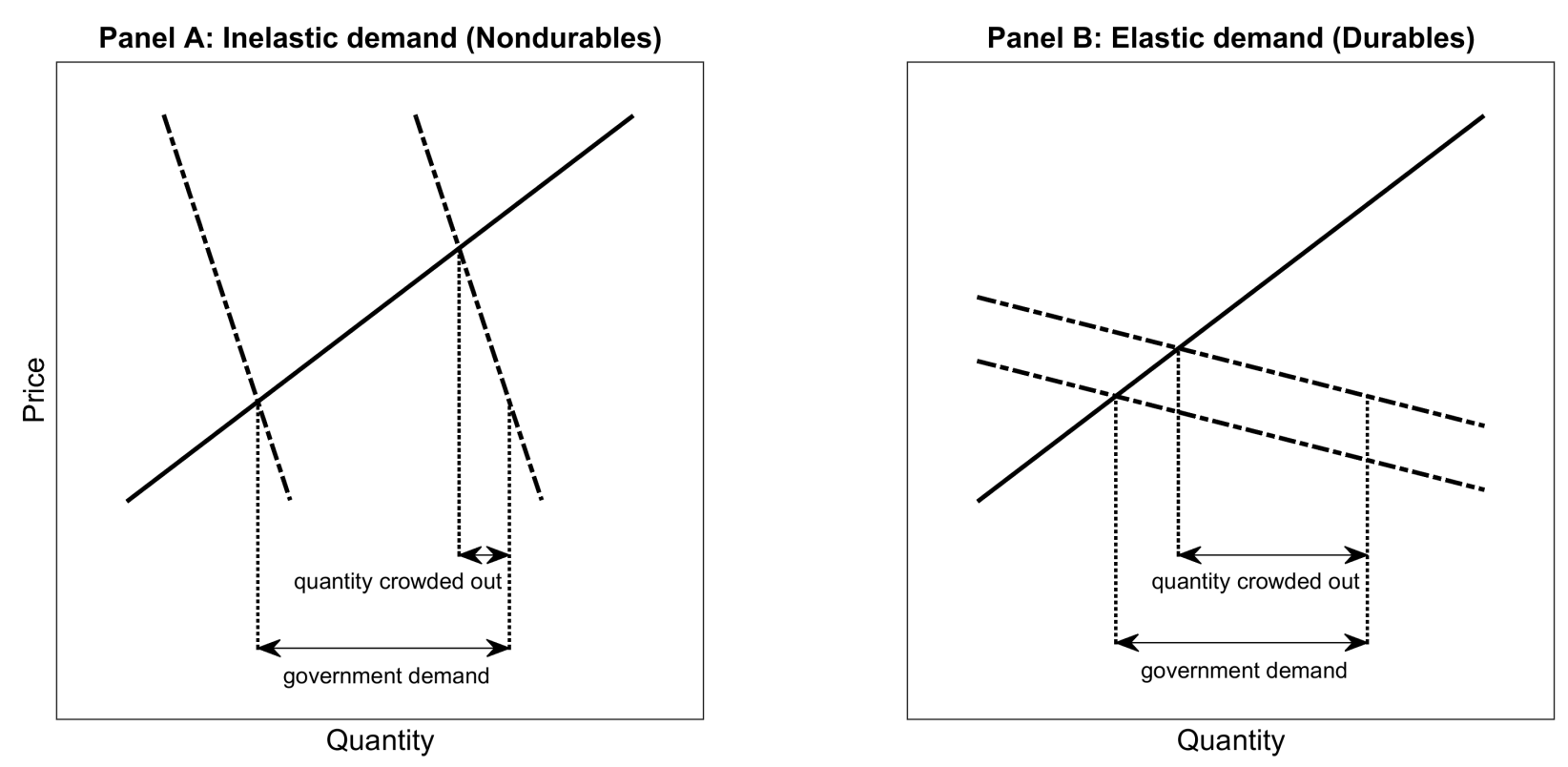

that follows to the empirical evidence in Section 3.

In the model described above, gross output in constant prices in sector $X$ is $G O_{X, t}=P_{X} X_{t}$ and value added is $V A_{X, t}=P_{X} X_{t}-P_{Z} M_{X, t}$. Also denote government purchases of good $X$ in constant prices by $G_{X, t}=P_{X} X_{G, t}$. Then the gross output and value added multipliers for sector $X$ are defined as $\mathrm{d} G O_{X, t} / \mathrm{d} G_{X, t}$ and $\mathrm{d} V A_{X, t} / \mathrm{d} G_{X, t}$. Since I will estimate these multipliers in Section 3 , it is of interest how these sector-level multipliers map into the policy relevant aggregate multiplier. When discussing the results below I pay particular attention to this relationship.

I next turn to two limiting approximations which allow me to solve for durable and nondurable multipliers analytically. The approximations require assumptions similar to those made above: I assume that $\beta$ approaches unity and that the depreciation rate of capital $\delta_{K}$ tends to zero. The economy is then shocked with a short-lived increase in government purchases, $X_{G}$, in the small sector. To preserve space I limit myself to the discussion of these results and provide details on the derivations in Appendix A.2.

\subsubsection{Spending on durable goods}

I first consider the case in which the small sector produces highly durable goods. 
Approximation result 1. Suppose $\delta_{K}$ and $\delta_{D}$ are arbitrarily close to zero and $\beta$ is arbitrarily close to 1 . Then, for a short-lived increase in spending, it is approximately true that (1) $\Delta X_{H, t} \approx$ $-\Delta X_{G, t}$, (2) the price $P_{X, t}$ remains unchanged, (3) the sectoral multipliers for gross output and value added are zero, $\frac{\mathrm{d} G O_{X, t}}{\mathrm{~d} G_{X, t}} \approx \frac{\mathrm{d} V A_{X, t}}{\mathrm{~d} G_{X, t}} \approx 0$, and (4) the aggregate multiplier is zero, $\frac{\mathrm{d} Y_{t}}{\mathrm{~d} G_{X, t}} \approx 0$.

Here $\Delta$ denotes the absolute deviation of a variable from steady state. Notice first that this result only requires the stated parametric assumptions. In particular, the result holds regardless of the functional forms of $u$ and $v$ and regardless of whether the $X$ sector requires intermediates for production. The result is also independent of the degree of price stickiness (as long as prices are not perfectly sticky), the relative sizes of the two sectors, and the precise specification of the monetary policy rule (equation 13).

Part (1) of the result states that every dollar spent by the government crowds out one dollar of private sector spending. If prices are not perfectly sticky, the small sector's supply curve is upwardsloping. Hence, a greater quantity would lead to a higher equilibrium price. In this limiting approximation, however, the private sector's demand for durable goods is perfectly elastic and any price increase would result in complete withdrawal from the market. Clearly, this cannot be an equilibrium outcome. Instead, the equilibrium quantity and price in the small sector both remain unchanged. This requires that private sector demand contracts dollar for dollar with greater government spending.

Since the equilibrium quantity in the small sector is unaffected by the fiscal expansion, the sectoral multipliers must be zero. It turns out that in this limiting case the aggregate multiplier is zero as well. The explanation of this result has three components. First, as noted above, the fiscal expansion has no effect on the small sector's output and therefore leaves factor demands unchanged. It follows that the household's labor and capital income remain the same and that there are no spillovers to the large sector through the demand for intermediate inputs. The second effect concerns the government's financing of the rise in spending. Because the expansion is by assumption brief, its effect on life-time income through taxation is very small. In fact, the approximation procedure treats the change in life-time income as negligible. It then follows that households neither change their labor supply nor their overall consumption demand. Finally, notice that both prices $P_{X}$ and $P_{Z}$ remain unchanged. Hence greater government spending does not raise inflation or output and no adjustment is required for the nominal interest rate. 
An important corollary of this approximation result is that fiscal multipliers need not be large at the zero lower bound (ZLB). As, among others, Christiano, Eichenbaum, and Rebelo (2011) and Woodford (2011) show, the multiplier is large whenever the fiscal expansion leads to inflation, and these inflationary forces are not offset by a higher policy rate. At the ZLB, higher inflation reduces the real rate, stimulating private consumption and therefore resulting in a large fiscal multiplier. However, when the government purchases highly durable goods, private spending is crowded out and inflation barely rises. The mechanism of greater demand leading to greater inflation and greater inflation leading to even greater demand is therefore not triggered. As a result, the durables multiplier remains low.

While the multipliers for long-lived durable goods are small at the ZLB, this is not always true for durable goods with intermediate service lives. I return to this issue in Section 4 in which I provide a quantitative analysis of durables multipliers at the ZLB.

\subsubsection{Spending on nondurable goods}

I next turn to the case in which the small sector produces a nondurable good.

Approximation result 2. Suppose $\delta_{D}=1, \delta_{K}$ is arbitrarily close to zero and $\beta$ is arbitrarily close to 1. Suppose further that prices are fully flexible, and that $u_{C D}=v_{X Z}=0$. Lastly, there is an additional technical assumption of little economic relevance which I discuss in Appendix A.2.

Then a short-lived increase in spending yields a gross output sectoral multiplier equal to

$$
\frac{\mathrm{d} G O_{X, t}}{\mathrm{~d} G_{X, t}} \approx \frac{\left(1+\eta_{X}^{-1}\right) \chi^{-1}-\left(\alpha+\eta_{X}^{-1}\right)}{\sigma_{D}\left(\alpha+\eta_{X}^{-1}\right) \frac{X_{H}}{X}+\left(1+\eta_{X}^{-1}\right) \chi^{-1}-\left(\alpha+\eta_{X}^{-1}\right)}
$$

and approximately equal sectoral value added and aggregate multipliers

$$
\frac{\mathrm{d} V A_{X, t}}{\mathrm{~d} G_{X, t}} \approx \frac{\mathrm{d} Y_{t}}{\mathrm{~d} G_{X, t}} \approx \frac{1-\alpha}{\sigma_{D}\left(\alpha+\eta_{X}^{-1}\right) \frac{X_{H}}{X}+\left(1+\eta_{X}^{-1}\right) \chi^{-1}-\left(\alpha+\eta_{X}^{-1}\right)} .
$$

Here, $\eta_{X}=\frac{v_{X}\left(N_{Z}, N_{X}\right)}{N_{X} v_{X X}\left(N_{Z}, N_{X}\right)}$. The relative price $P_{X, t} / P_{Z, t}$ rises in response to greater spending.

When the small sector produces a nondurable good, all three multipliers are positive. More precisely, they are bounded between zero and one, a feature common in neoclassical environments. Additionally, the sectoral value added multiplier and the aggregate multiplier are again approxi- 
mately equal, implying that sectoral multipliers are of direct policy interest.

I next discuss how various parameters affect the multipliers. The main property that this paper emphasizes is the multipliers' dependence on the intertemporal elasticity of substitution $\sigma_{D}$. The greater $\sigma_{D}$ the smaller the multipliers. As $\sigma_{D}$ approaches infinity all three multipliers tend to zero, the same value that multipliers of highly durable goods take.

To understand the role of the remaining parameters, I consider two polar cases. Suppose first that no intermediates are required for production $(\chi=1)$. Then it is easy to show that all three multipliers approximately equal

$$
\frac{1-\alpha}{1-\alpha+\sigma_{D}\left(\alpha+\eta_{X}^{-1}\right) \frac{X_{H}}{X}} .
$$

This formula is identical to that in Hall (2009, p. 199). It illustrates clearly that the multiplier is increasing in the labor supply elasticity, $\eta_{X}$, and decreasing in the capital share, $\alpha$, reflecting the fact that capital is a fixed factor in the short run.

I next turn to the opposite case in which $\chi \rightarrow 0$ so that the small sector almost exclusively uses intermediates in production. It then follows that the sectoral multiplier for gross output, $\frac{\mathrm{d} G O_{X, t}}{\mathrm{~d} G_{X, t}}$, approaches unity while the sectoral multiplier for value added and the aggregate multiplier tend to zero. What is the intuition behind these results?

A gross output multiplier of unity implies that the small sector expands one-for-one with greater government demand. Since additional output is almost exclusively produced from intermediates, it is clear that value added in the small sector remains close to zero. It can also be shown that

$$
\Delta M_{X, t} \approx-\left(\Delta I_{X, t}+\Delta I_{Z, t}\right)
$$

so that purchases of intermediates crowd out investment in the large hybrid sector dollar for dollar. Hence, while the small sector expands one-for-one, this expansion has no effect on production in the large sector and total value added (GDP) remains unchanged. We therefore encounter a second instance in which the crowding out of durable goods with large intertemporal elasticity of substitution - in this case investment goods - implies a low multiplier.

Although this finding is certainly extreme and crucially relies on the assumption that the large sector's output can be used for investment, the approximation clearly illustrates how sectoral link- 
ages affect fiscal multipliers: If government purchases, either directly or indirectly through intermediate input linkages, raise the demand for durable goods, they largely crowd out private sector demand. If, in contrast, government purchases are targeted at nondurable goods, there is less crowding out and the multipliers are larger.

\subsection{Numerical results}

I next use an exact (linear) solution of the model to confirm that the durables multiplier is relatively small. Before proceeding, however, I modify the model slightly. In order to avoid the extreme crowding out effects that greater intermediate purchases cause in the large hybrid sector, I introduce investment adjustment costs. These adjustment costs reflect the fact that some intermediates are nondurable in nature and therefore have a less elastic demand function than those intermediates that are durable.

\subsubsection{Calibration}

The length of a period is a quarter and households discount the future with discount factor $\beta=0.99$. The flow utility function is given by

$$
u\left(C_{t}, D_{H, t}\right)=\left(1-\frac{1}{\sigma}\right)^{-1}\left(\left[\omega\left(C_{t}\right)^{\frac{\rho-1}{\rho}}+(1-\omega)\left(D_{H, t}\right)^{\frac{\rho-1}{\rho}}\right]^{\frac{\rho}{\rho-1}}\right)^{1-\frac{1}{\sigma}} .
$$

Consistent with the estimates in Hall (1988) and Cashin and Unayama (2012), I select an intertemporal elasticity of substitution $\sigma$ of 0.25 . In the baseline calibration, I further assume that the elasticity of substitution $\rho$ between $C$ and $D_{H}$ is (arbitrarily close to) 1 . I explore alternative values in robustness exercises. The preference weight $\omega$ is chosen so that value added in the small sector is one hundredth of total value added.

I assume that the disutility of labor is given by

$$
v\left(N_{X, t}, N_{Z, t}\right)=\varphi_{X} \frac{\left(N_{X, t}\right)^{1+\frac{1}{\eta}}}{1+\frac{1}{\eta}}+\varphi_{Z} \frac{\left(N_{Z, t}\right)^{1+\frac{1}{\eta}}}{1+\frac{1}{\eta}} .
$$

This specification implies that labor is immobile across sectors, an assumption I also relax in robustness exercises. I set the labor supply elasticity $\eta$ to unity. This value is broadly consistent with recent suggestions in the literature Kimball and Shapiro 2008, Hall 2009, and Chetty et al. 
2011). ${ }^{8}$

Turning to the production side of the model, I choose $\alpha=1 / 3$ as is standard in the literature. Consistent with an intermediate input share of roughly 55 percent in the 2007 Make and Use Tables, I calibrate $\chi$ to 0.45 . Further, I set $\varepsilon$ to 6 , implying a steady state mark-up of 20 percent. In my choice of the the price stickiness parameters $\theta_{X}$ and $\theta_{Z}$, I follow Gali (2008) and assume that both equal $2 / 3$. The depreciation rates of both types of capital are set to 0.025 , implying approximately a 10 percent annual depreciation rate. I show results for various alternative values of $\delta_{D}$, including $\delta_{D}=1$ so that the small sector produces a nondurable good.

In steady state, the government purchases one fifth of the output in the small sector. I calibrate the persistence $\varrho_{X}$ of the spending process (10) to 0.75 . This value implies that the fiscal expansion largely dissipates after eight quarters, mimicking the spending trajectory of the American Recovery and Reinvestment Act. ${ }^{9}$ The monetary authority follows a simple Taylor rule, that is, I replace the general rule (13) by $i_{t}=\beta^{-1}-1+\phi_{\pi} \pi_{t}+\phi_{Y} \tilde{Y}_{t}$. Here, the tilde denotes percent deviation from steady state. In the baseline calibration I set $\phi_{\pi}=1.1$ and $\phi_{Y}=0$. Notice that this policy rule satisfies the Taylor principle, ensuring equilibrium determinacy as shown in Bullard and Mitra (2002). I consider a more hawkish parameterization of the Taylor rule in Appendix A.3.

Finally, I assume that capital investment at time $t$ is subject to adjustment costs of the form

$$
K_{j, t-1} \frac{\zeta_{K}}{2}\left(\frac{I_{j, t}}{K_{j, t-1}}-\delta_{K}\right)^{2}, j \in\{X, Z\}
$$

In the baseline calibration, summarized in Table $1, \zeta_{K}$ is set to 20 . This value is slightly higher than the 17 chosen by Christiano, Eichenbaum, and Rebelo (2011) who base their calibration on Eberly, Rebelo, and Vincent (2008).

\subsubsection{Simulation results}

I next turn to the question how the economy's reaction to a government spending shock depends on the depreciation rate $\delta_{D}$. I consider four different cases. First, I set $\delta_{D}=1$ so that the small sector produces nondurables. Second, I set $\delta_{D}=0.083-$ a value consistent with a 3 year service life. The Bureau of Economic Analysis (undated) estimates for example the service lives of tires

\footnotetext{
${ }^{8}$ Once $\omega$ and the remaining parameters are fixed, the values of $\varphi_{X}$ and $\varphi_{Z}$ do not affect equilibrium dynamics.

${ }^{9}$ The Congressional Budget Office estimates that 78 percent of total spending had occurred by September 2011 (see https://www.cbo.gov/publication/42682).
} 
Table 1: Baseline calibration

\begin{tabular}{lcl}
\hline \hline Parameter & Value & Description \\
\hline$\beta$ & 0.99 & Discount factor \\
$\eta$ & 1 & Labor supply elasticity \\
$\sigma$ & 0.25 & Intertemporal elasticity of substitution \\
$\rho$ & 0.9999 & Elasticity of substitution between goods in the X and the Z sector \\
$\alpha$ & $1 / 3$ & Capital share \\
$\chi$ & 0.45 & $1-\chi$ is the cost share of intermediates \\
$\varepsilon$ & 6 & Elasticity of substitution in aggregator \\
$\theta_{X}, \theta_{Z}$ & $2 / 3$ & Price stickiness \\
$\delta_{K}$ & 0.025 & Depreciation rate of capital \\
$X_{H} / X$ & 0.80 & Fraction of private sector spending in steady state \\
$\omega$ & 0.9693 & Preference weight on consumption of Z sector goods \\
$\varrho_{X}$ & 0.75 & Persistence of fiscal policy shock \\
$\phi_{\pi}$ & 1.1 & Taylor rule response coefficient on inflation \\
$\phi_{Y}$ & 0 & Taylor rule response coefficient on output \\
$\zeta_{K}$ & 20 & Capital adjustment costs \\
\hline
\end{tabular}

and software at 3 years. Third, I select a value of $\delta_{D}=0.018$. This value corresponds to a service life of 14 years (e.g. furniture). Lastly, I consider a very long-lived durable. According to the BEA, new 1-to-4-unit structures have service lives of 80 years, implying a quarterly depreciation rate of approximately $\delta_{D}=0.003$. Figure 2 shows the impulse response functions of a 100 unit increase of government spending in the $X$ sector.

Panel A displays the fiscal expansion in the public sector and Panel B shows the private sector response. If the small sector produces a nondurable good, private sector spending barely changes. Since there is very little crowding out, production expands almost one-for-one with public spending. This is shown in Panel C. The aggregate multiplier is near 0.75 (Panel D) and the gross multiplier in the $X$ sector is close to unity (Panel E). If, in contrast, the small sector produces durable goods, the multipliers are much smaller.

The lower the depreciation rate the more private sector spending is crowded out. When the $X$ sector produces a moderately durable good with a 3 year service life $\left(\delta_{D}=0.083\right)$, private sector spending falls substantially more after the spending shock. All multipliers, gross output, value added, and aggregate, fall to roughly two thirds of the nondurable goods multiplier. For a service life of 14 years, the multipliers fall to about $1 / 3$ of the nondurables multiplier. As the depreciation 
Figure 2: Impulse response functions for a government spending shock
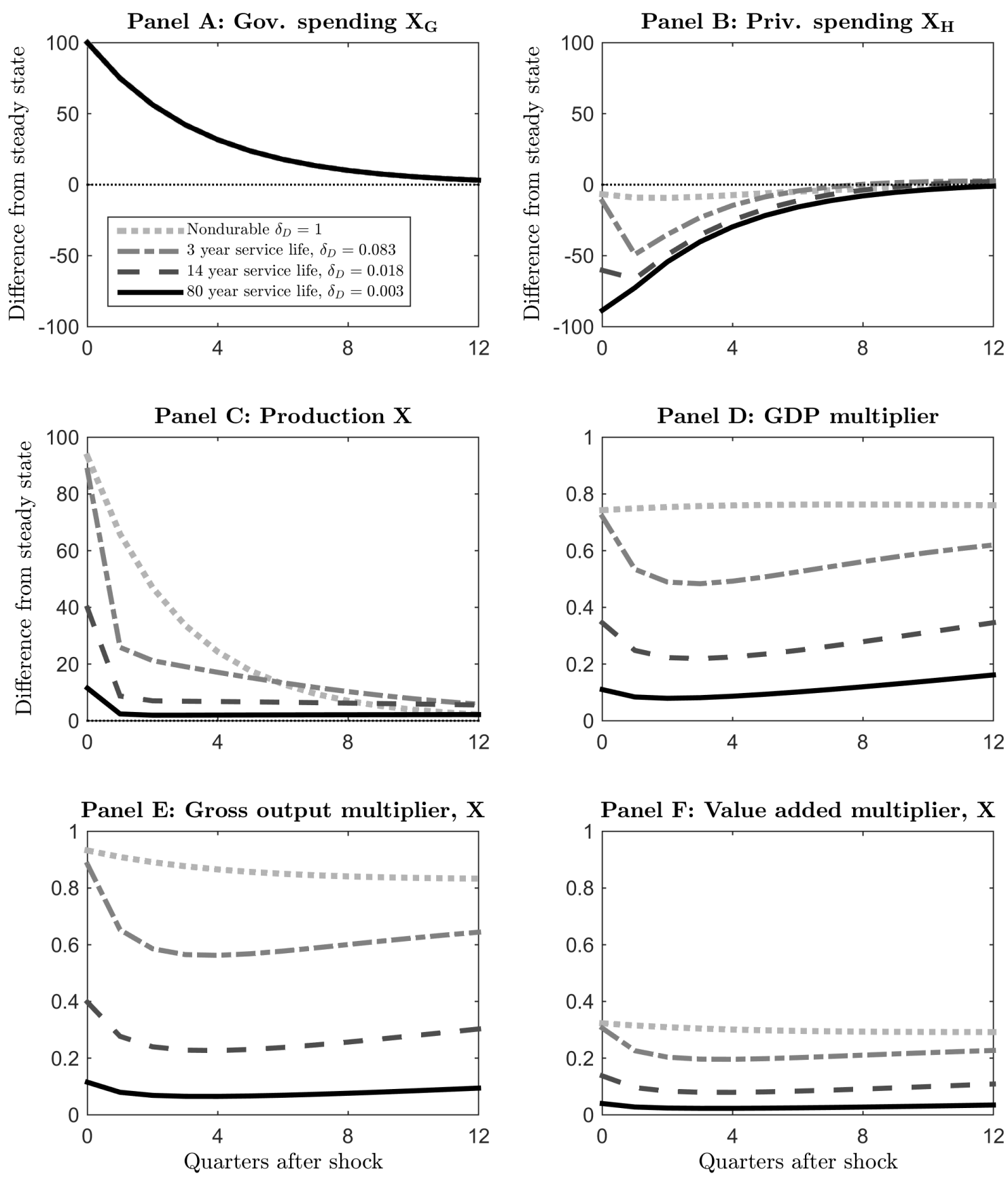

Notes: The figure plots impulse response functions for various calibrations. Panels A to C are expressed in absolute deviations from steady state. The impulse is a 100 unit increase of government spending in sector $X$. 
rate further approaches zero the multipliers gradually shrink to zero. The model therefore predicts that infrastructure investment which crowds out private sector construction has a very small fiscal multiplier of roughly 0.1 .

These impulse response functions corroborate the results presented earlier: The demand for durable goods is highly elastic and easily crowded out. However, they yield one additional insight. Because all real variables of the model are stationary, they return to their steady state values in the long run. This model feature implies that any demand that is temporarily crowded out has to be made up in the long run as households replenish their stock of durables. In fact, Panel B shows that households' purchases of the durable goods rise above zero roughly 10 quarters after the shock.

An implication of this delayed demand boost is that the multipliers of durable goods begin to rise about 4 quarters after the shock. From the viewpoint of stabilization policy, it is an unfortunate fact that private demand picks up only after the fiscal expansion ends and the pressure on prices recedes. For short-lived spending shocks the economy will never enjoy increased government and private sector demand at the same time. I report the impulse response functions of the price in sector $X$ and the nominal interest rate in Figure A1 in Appendix A.4.

I finally turn to the question of what sectoral multipliers teach us about aggregate multipliers. In the limiting approximations above, crowding out of capital investment was perfect and, as a result, the aggregate multipliers were equal to the sectoral value-added multipliers. However, when the depreciation rate of capital is higher and investment is subject to adjustment costs, as in the calibrations shown here, crowding out is imperfect. The aggregate multiplier is now greater than the sectoral value added multiplier. In fact, for all four calibrations shown in Figure 2, the aggregate multipliers lie above the sectoral value added multipliers and are quite similar to or somewhat below the gross output multipliers. As I show in Appendix A.3, the rule of thumb that the aggregate multipliers are slightly smaller than the sectoral gross output multipliers is robust for a number of alternative calibrations.

\section{Empirical evidence}

The main objective in this section is to test whether the data support the hypothesis that the durables multiplier is smaller than the nondurables multiplier. I begin the analysis using national 
accounts data and find that the evidence supports the hypothesis. I then turn to an analysis at the industry level and again find evidence for smaller multipliers of durable goods purchases.

\subsection{Evidence based on aggregate data}

For the analysis of aggregate data, I adopt a specification similar to Hall (2009) and Barro and Redlick (2011), namely

$$
\frac{Y_{t}-Y_{t-1}}{Y_{t-1}^{T}}=\alpha+\mu_{X} \frac{G_{X, t}-G_{X, t-1}}{Y_{t-1}^{T}}+\mu_{C} \frac{G_{C, t}-G_{C, t-1}}{Y_{t-1}^{T}}+\nu R N_{t}+\varepsilon_{t+1} .
$$

In this equation $Y_{t}$ is GDP, $Y_{t}^{T}$ is trend GDP, $G_{X, t}$ is military spending on durable goods, $G_{C, t}$ is military spending on nondurable goods, and $R N_{t}$ is Ramey's (2011) defense news variable. Ramey's news variable is constructed from narrative records and measures the present value of new military spending at the time of announcement. The variable mostly captures defense spending 3 to 5 years into the future and is expressed as a fraction of GDP.

I control for the announcement of future spending to isolate the effect of actual spending on durable and nondurable goods. According to standard theory, the announcement of greater future spending reduces households' life-time wealth and increases their labor supply. $\nu$ is therefore expected to be positive. The main reason for including this control is that announcements of future spending could be correlated with one of the spending variables but not the other. If, for example, the public learns about a military buildup at the same time as first investments into equipment are made, the estimate of $\mu_{X}$ would be biased upward without the control for news on future spending. Note that when $\mu_{X}$ and $\mu_{C}$ are estimated based on specification (19), these "multipliers" are purged of announcement effects and thus understate the total effect of military spending. ${ }^{10}$

Consistent estimation of the multipliers $\mu_{X}$ and $\mu_{C}$ requires the commonly made assumption that the state of the business cycle does not affect whether the U.S. engages in military conflict (e.g. Ramey and Shapiro, 1998, Hall, 2009). I use annual national accounts data for the estimation. Details are available in Appendix B.1.

Table 2 shows the results. The output multipliers are quite different for durable and nondurable goods. For the sample from 1929 to 2014 the estimate of $\mu_{C}$ is 0.49 . When World War II is excluded,

\footnotetext{
${ }^{10}$ Based on the argument in Barro and Redlick (2011) the total size of the durables and nondurables multipliers should roughly be $\mu_{X}+4 \cdot \nu$ and $\mu_{C}+4 \cdot \nu$.
} 
Table 2: Estimates of durable and nondurable goods multipliers

\begin{tabular}{|c|c|c|c|c|c|c|}
\hline \multirow[b]{3}{*}{ Dependent variable } & \multicolumn{6}{|c|}{ Sample } \\
\hline & \multicolumn{3}{|c|}{ 1929-2014 } & \multicolumn{3}{|c|}{$1947-2014$} \\
\hline & $\mu_{X}$ & $\mu_{C}$ & $\nu$ & $\mu_{X}$ & $\mu_{C}$ & $\nu$ \\
\hline Output & $\begin{array}{c}0.04 \\
(0.32)\end{array}$ & $\begin{array}{c}0.49 \\
(0.08)\end{array}$ & $\begin{array}{c}0.065 \\
(0.011)\end{array}$ & $\begin{array}{l}-1.19 \\
(2.24)\end{array}$ & $\begin{array}{c}0.83 \\
(0.43)\end{array}$ & $\begin{array}{c}0.041 \\
(0.007)\end{array}$ \\
\hline Private consumption & $\begin{array}{l}-0.63 \\
(0.20)\end{array}$ & $\begin{array}{c}0.02 \\
(0.04)\end{array}$ & $\begin{array}{c}0.024 \\
(0.008)\end{array}$ & $\begin{array}{l}-1.13 \\
(1.03)\end{array}$ & $\begin{array}{c}0.14 \\
(0.20)\end{array}$ & $\begin{array}{c}0.012 \\
(0.003)\end{array}$ \\
\hline Private investment & $\begin{array}{l}-0.89 \\
(0.26)\end{array}$ & $\begin{array}{c}0.00 \\
(0.05)\end{array}$ & $\begin{array}{c}0.032 \\
(0.004)\end{array}$ & $\begin{array}{l}-1.12 \\
(0.93)\end{array}$ & $\begin{array}{c}0.09 \\
(0.18)\end{array}$ & $\begin{array}{c}0.028 \\
(0.003)\end{array}$ \\
\hline $\begin{array}{l}\text { Private consumption of } \\
\text { nondurables and services }\end{array}$ & $\begin{array}{l}-0.54 \\
(0.16)\end{array}$ & $\begin{array}{c}0.03 \\
(0.04)\end{array}$ & $\begin{array}{c}0.022 \\
(0.006)\end{array}$ & $\begin{array}{l}-0.95 \\
(0.95)\end{array}$ & $\begin{array}{c}0.17 \\
(0.19)\end{array}$ & $\begin{array}{c}0.009 \\
(0.003)\end{array}$ \\
\hline $\begin{array}{l}\text { Private investment plus } \\
\text { private durables consumption }\end{array}$ & $\begin{array}{l}-0.98 \\
(0.33)\end{array}$ & $\begin{array}{c}0.00 \\
(0.06)\end{array}$ & $\begin{array}{c}0.034 \\
(0.005)\end{array}$ & $\begin{array}{l}-1.30 \\
(1.01)\end{array}$ & $\begin{array}{c}0.07 \\
(0.20)\end{array}$ & $\begin{array}{c}0.030 \\
(0.003)\end{array}$ \\
\hline Net exports & $\begin{array}{c}0.00 \\
(0.08)\end{array}$ & $\begin{array}{l}-0.05 \\
(0.01)\end{array}$ & $\begin{array}{c}-0.002 \\
(0.003)\end{array}$ & $\begin{array}{l}-0.23 \\
(0.32)\end{array}$ & $\begin{array}{c}0.01 \\
(0.08)\end{array}$ & $\begin{array}{l}-0.007 \\
(0.001)\end{array}$ \\
\hline
\end{tabular}

Notes: The table reports the coefficient estimates of $\mu_{X}, \mu_{C}$, and $\nu$ as defined in equation (19). Newey-West standard errors are reported in parentheses.

the multiplier rises to 0.83 . In contrast, the estimates of $\mu_{X}$ are close to zero or negative, supporting the theoretical predictions that durables multipliers are smaller than nondurables multipliers. Yet, the standard errors are too large to reject the null hypothesis that $\mu_{C}$ equals $\mu_{X}$. As expected, the estimates of $\nu$ are positive.

I next replace GDP in the numerator on the left hand side of equation (19) with a number of other variables to estimate how government spending on durable and nondurable goods crowds out private sector spending. These are consumption, investment, consumption of nondurables and services, investment plus durable goods consumption, and net exports. It is striking how consistently the coefficient on nondurables is estimated to be essentially zero. Hence, there is little, if any, crowding out when the government purchases nondurable goods. There is, however, crowding out when the government purchases durable goods. For the sample from 1929 to 2014 the 
estimate of $\mu_{X}$ is significantly negative for all four measures of private consumption and investment. The coefficients are near negative one for investment and investment plus durables consumption, suggesting that there is almost perfect crowding out. It is less clear how the negative coefficient on durables spending in the consumption equation should be interpreted. When consumption is limited to nondurables and services, the estimates of $\mu_{X}$ move slightly towards zero. Although this suggests that there is indeed more crowding out of durables consumption, the estimates of $\mu_{X}$ remain negative.

The model in section 2 suggests that the durables multiplier is small because the private sector substitutes intertemporally when the government raises spending. An alternative explanation is that the private sector substitutes towards imported goods. If this was the case, greater government spending should be accompanied by lower net exports and a smaller drop in investment. The last line in table 2 shows that the response of net exports is negligibly small. Hence, the data do not support the alternative hypothesis that the durables multiplier is small because of substitution towards foreign goods.

From 1972 onwards, the BEA provides a more detailed breakdown of military spending. Evidence based on this data again suggests that fiscal policy is less effective when the government purchases durable goods. I discuss data, estimation strategy and results in Appendix B.2 and next turn to evidence based on industry-level data.

\subsection{Evidence based on industry-level data}

In this section I estimate fiscal multipliers at the industry level: How much does industry output rise if the government spends $1 \$$ on goods in this industry? Moving towards less aggregate data has the benefit of substantially raising the available data and therefore statistical power. As I will discuss below, this analysis has the additional advantage of relaxing the identifying assumptions. Yet, there is a mild cost: The policy relevant aggregate multipliers generally differ somewhat from the estimated industry-level multipliers. Since I established a close connection between these two types of multipliers in section 2 , I view these costs as relatively small. 


\subsubsection{Data}

The empirical analysis at the industry level is based primarily on two data sources, the NBER-CES Manufacturing Industry Database and the military prime contract files. The NBER-CES database contains annual data on, among other things, gross output, value added, cost of materials, expenditures on energy, and employment, along with various deflators. It ranges from 1958 to 2009 and covers all manufacturing industries. The database is constructed mainly from the Annual Survey of Manufactures and the Census of Manufactures, but complemented with additional information from the Bureau of Economic Analysis, the Bureau of Labor Statistics, and the Federal Reserve Board. A detailed description of this database is provided by Bartelsman and Gray (1996) and Becker, Gray, and Marvakov (2013).

The military prime contract files include information on all military prime contracts with values above the minimum threshold of $\$ 10,000$ up to 1983 and $\$ 25,000$ thereafter. They can be downloaded for the period from 1966 to 2003 from the U.S. National Archives. I complement the prime contract files with data from USAspending.gov, a government website dedicated to promoting transparency of federal spending. The data from USAspending.gov is available from 2000 onwards. A comparison of the two data sources for the overlapping years from 2000 to 2003 reveals only negligible differences. The analysis below is based on all contracts that are awarded to firms in the United States.

Unfortunately, the data on defense spending is not easily matched to different industries. While the NBER-CES database is available for both SIC- and NAICS-based industry definitions, the military prime contract files contain SIC codes only for the relatively brief period from 1989 to 2000 and NAICS codes from 2000 onwards. Instead, military purchases are classified according to the Federal Procurement Data System which assigns a unique Product Service Code (PSC) or Federal Supply Code (FSC) to each contract since 1966.

To obtain military spending at the industry level I construct a concordance from the FSC/PSC classification to 4-digit SIC codes. The concordance is based on the military prime contract files from 1989 to 2000 which contain both, FSC/PSC and SIC codes. Details on the construction of this concordance as well as further information on the data and the FSC/PSC classification system are available in Appendix C.1. Because the FSC/PSC system underwent a major revision in 1979, the concordance is only valid thereafter. This leaves me with a sample of annual data from 1979 
to 2009. I adopt the SIC classification of durable and nondurable goods.

Due to concerns about measurement error (see below) and because one would not expect that small changes in military spending give rise to measurable changes in economic activity, I limit the sample to industries in which the military purchases at least 1 percent of gross output, on average. Examples of dropped industries include Greeting Cards (SIC 2771) and Women's Footwear (SIC 3144). I also drop industries with little private sector demand. These industries are problematic for testing the hypothesis of smaller multipliers for spending on durable goods because with little private sector demand to begin with, there is little room for crowding out. In the complete absence of private sector demand, the theory discussed above does not apply and the sectoral multiplier should be unity regardless of whether the sector produces durable or nondurable goods. I therefore drop industries with average values of military purchases per industry gross output of greater than 0.35. ${ }^{11}$ Examples here include Tanks and Tank Components (SIC 3795) and Ammunition, except for Small Arms (SIC 3483). The final sample comprises 35 nondurables and 76 durables industries. I list all industries in the sample in Appendix C.2.

\subsubsection{Empirical strategy}

\section{Specification}

I first estimate impulse response functions using Jordà's (2005) local projection method and then construct multipliers from the estimated impulse response functions. The baseline specification is

$$
\begin{aligned}
\frac{Y_{i, t+h}-Y_{i, t-1}^{T}}{V A_{i, t-1}^{T}}= & \alpha_{h} \frac{G_{i, t}-G_{i, t-1}^{T}}{V A_{i, t-1}^{T}}+\sum_{k=1}^{2} \beta_{h}^{k} \frac{Y_{i, t-k}-Y_{i, t-k-1}^{T}}{V A_{i, t-k-1}^{T}} \\
& +\sum_{k=1}^{2} \gamma_{h}^{k} \frac{G_{i, t-k}-G_{i, t-k-1}^{T}}{V A_{i, t-k-1}^{T}}+\delta_{i, h}+\zeta_{t, h}+\varepsilon_{i, t+h},
\end{aligned}
$$

for $h=0,1, \ldots, 4$. In this equation $Y_{i, t}$ is a generic variable of interest of industry $i$ at time $t, G_{i, t}$ is defense spending, and $V A_{i, t}$ is value added. The superscript $T$ indicates that the variable in question is an HP-filtered trend.

I estimate equation (20) separately for durable and nondurable goods industries to obtain the objects of interest $\left\{\alpha_{h}\right\}_{h=0}^{4}$. These parameters represent the impulse response coefficients for the

\footnotetext{
${ }^{11}$ Other thresholds leave the results essentially unchanged.
} 
impact year, $h=0$, and four subsequent years. The specification controls for two lags of the deviations of the dependent variable and defense spending from trend, as well as time and industry fixed effects $\delta_{i, h}$ and $\zeta_{t, h}$.

The time fixed effects play a key role in specification (20). They soak up disturbances that affect all industries symmetrically, notably monetary policy shocks and certain tax policy changes. Additionally, the time fixed effects control for announcements of greater future spending, at least to the extend that all sectors are affected equally. Notice that since I estimate equation (20) separately for durable and nondurable goods industries all coefficients are allowed to differ by industry type.

A potential concern with specification (20) is that the impulse response coefficients $\left\{\alpha_{h}\right\}_{h=0}^{4}$ depend on the smoothness of the trends required for constructing the left and right-hand side variables. To err on the safe side I extract very smooth trends with a smoothing parameter of 1600 for annual data. I also test the robustness of my results for alternative values of this parameter.

\section{Identification}

As Nekarda and Ramey (2011) discuss in detail, an industry-level analysis of government spending may suffer from an endogeneity problem. Technological progress in a particular industry can lead both to greater sales to the private sector and to increased defense spending as the military upgrades its equipment. The bias resulting from the estimation of (20) by OLS would inflate the impulse response coefficients above their true levels.

On the other hand, measurement error in defense spending may bias the coefficients towards zero. Measurement error is a concern for the following reason. In the military prime contract files, every contract is assigned a single FSC/PSC code. The documentation of the files reveals occasional difficulties of the procurement staff to select a single code, as some contracts include purchases of different types of goods. ${ }^{12}$ Although the staff is instructed to assign the FSC/PSC code whose description best fits the contract, it is likely that the limitation to one code per contract induces measurement error. A second source of error is the use of the concordance to map FSC/PSC codes to SIC industry definitions.

To avoid or reduce these biases I construct a Bartik-type instrument from total defense spending, i.e. spending summed over all manufacturing industries (Bartik, 1991). More precisely, I construct

\footnotetext{
${ }^{12}$ For example, guns, up to $30 \mathrm{~mm}$ (FSC 1005) and guns, over 30mm up to $75 \mathrm{~mm}$ (FSC 1010) are two separate categories. It is conceivable that purchases of both types of guns were part of the same contract.
} 
the variable

$$
\frac{1}{5} \sum_{s=1979}^{1983} \frac{G_{i, s} / G O_{i, s}}{G_{s} / G O_{s}} \cdot \frac{G_{t}-G_{t-1}^{T}}{V A_{t-1}^{T}} .
$$

The first term in this expression is a five-year average of the industry-specific military spending share divided by the aggregate military spending share. It scales the aggregate military spending series (the second term) so as to generate industry-specific variation. The idea is that those industries in which the military purchases a greater fraction of output, on average, also experience greater changes in spending in response to aggregate military buildups or drawdowns. ${ }^{13}$ Because all military spending variables on the right-hand side of baseline specification (20) are potentially endogenous, I use (21) and its two lags as instruments.

Two assumptions are required for (21) to satisfy the exclusion restriction. First, and recalling that specification (20) contains time fixed effects, the relative performance of industries does not affect whether the U.S. government engages in an aggregate military buildup. This assumption rules out a reverse causality problem of the type discussed above. Second, it is not the case that aggregate military spending changes other determinants of industry-level output after controlling for the right-hand side variables of specification (20). As noted above, monetary and tax policy as well as a nationwide draft do not pose a threat to identification because the effects should be roughly symmetric within durable or nondurables industries and will therefore be soaked up by the time fixed effect. A concern would arise, however, if the cyclicality in the absence of military spending was greater in industries which receive greater fractions of government spending. While this condition is inherently not testable, it is reassuring to note that the average standard deviation of value added growth in industries which receive below and above median military spending are very similar.

I next turn to the first stage of the estimation. Table 3 summarizes the Angrist-Pischke Fstatistics of excluded instruments and their p-values when the dependent variable is value added for the time horizons from $h=0, \ldots, 4$. The smallest F-statistic in Table 3 takes the value 15, implying that the instruments are strong. In principle, the first stage for specification (20) is different for every dependent variable $Y_{i, t}$ (due to the lags on the right-hand side). In practice, however, the Angrist-Pischke F-statistics are virtually identical. I therefore only report the details for value added.

\footnotetext{
${ }^{13}$ Nekarda and Ramey (2011) and Nakamura and Steinsson (2014) use similar approaches to construct instruments.
} 


\section{Table 3: First stages}

First stages for nondurable goods industries

\begin{tabular}{|c|c|c|c|c|c|c|}
\hline First stage dep. variable & Horizon $h$ & 0 & 1 & 2 & 3 & 4 \\
\hline \multirow{4}{*}{$\frac{G_{i, t}-G_{i, t-1}^{T}}{V A_{i, t-1}^{T}}$} & AP F-statistic & 21.3 & 30.5 & 38.6 & 46.3 & 39.2 \\
\hline & p-value & 0.00 & 0.00 & 0.00 & 0.00 & 0.00 \\
\hline & R-squared & 0.42 & 0.43 & 0.44 & 0.44 & 0.44 \\
\hline & AP F-statistic & 15.0 & 17.6 & 22.5 & 21.9 & 22.0 \\
\hline \multirow{3}{*}{$\frac{G_{i, t-1}-G_{i, t-2}^{T}}{V A_{i, t-2}^{T}}$} & p-value & 0.00 & 0.00 & 0.00 & 0.00 & 0.00 \\
\hline & R-squared & 0.42 & 0.42 & 0.42 & 0.43 & 0.43 \\
\hline & AP F-statistic & 41.1 & 54.8 & 54.8 & 54.5 & 62.9 \\
\hline \multirow[t]{2}{*}{$\frac{G_{i, t-2}-G_{i, t-3}^{T}}{V A_{i, t-3}^{T}}$} & p-value & 0.00 & 0.00 & 0.00 & 0.00 & 0.00 \\
\hline & R-squared & 0.38 & 0.43 & 0.43 & 0.44 & 0.44 \\
\hline Observations & & 967 & 932 & 897 & 862 & 827 \\
\hline
\end{tabular}

First stages for durable goods industries

\begin{tabular}{|c|c|c|c|c|c|c|c|}
\hline First stage dep. variable & & Horizon $h$ & 0 & 1 & 2 & 3 & 4 \\
\hline \multirow{4}{*}{$\frac{G_{i, t}-G_{i, t-1}^{T}}{V A_{i, t-1}^{T}}$} & AP F-statistic & & 225.5 & 249.3 & 353.9 & 402.8 & 271.2 \\
\hline & p-value & & 0.00 & 0.00 & 0.00 & 0.00 & 0.00 \\
\hline & R-squared & & 0.44 & 0.48 & 0.52 & 0.54 & 0.54 \\
\hline & AP F-statistic & & 225.8 & 280.4 & 282.8 & 229.2 & 162.8 \\
\hline \multirow{3}{*}{$\frac{G_{i, t-1}-G_{i, t-2}^{T}}{V A_{i, t-2}^{T}}$} & p-value & & 0.00 & 0.00 & 0.00 & 0.00 & 0.00 \\
\hline & R-squared & & 0.48 & 0.51 & 0.53 & 0.53 & 0.55 \\
\hline & AP F-statistic & & 339.4 & 375.0 & 456.4 & 349.6 & 342.2 \\
\hline \multirow[t]{2}{*}{$\frac{G_{i, t-2}-G_{i, t-3}^{T}}{V A_{i, t-3}^{T}}$} & $\mathrm{p}$-value & & 0.00 & 0.00 & 0.00 & 0.00 & 0.00 \\
\hline & R-squared & & 0.52 & 0.53 & 0.54 & 0.56 & 0.56 \\
\hline Observations & & & 2115 & 2039 & 1963 & 1887 & 1811 \\
\hline
\end{tabular}

Notes: The table shows the first stages of the 2SLS estimator of specification (20) when the dependent variable is value added. For all other dependent variables, the F-statistics are virtually identical. The instruments are (21) and its two lags. AP F-statistic stands for Angrist-Pischke F-statistic of excluded instruments and the subsequent lines show the associated p-values. 


\subsubsection{Results}

Figure 3 shows the estimated impulse response functions for the baseline sample. A unit increase in military spending leads to additional spending in subsequent years (Panel A). The impulse response functions for both types of industries begin to fall in year five and return to zero 6 to 7 years after the shock (see Figure C2, Appendix C.3). Hence, the spending increase is more persistent than a typical stimulus program such as the ARRA. I show in Appendix A.3 that the model predicts a difference of factor two between the nondurables and the durables multiplier for shocks with this persistence.

Panel B shows the dynamic responses of gross output associated with these spending paths. Consistent with the hypothesis of greater crowding out in durable goods industries, the effect of military spending on gross output is quite small. In contrast, nondurables industries expand substantially.

Panel $\mathrm{C}$ displays the responses of value added. In both types of industries value added rises significantly above zero and, again, the dynamic response for durables industries lies below that for nondurables industries. Additionally, in nondurables industries the rise in valued added is accompanied by increased purchases of materials (Panel D), although the standard errors are fairly large. By contrast, the costs of materials change little in durables industries. ${ }^{14}$ Panel $\mathrm{E}$ shows the impulse response functions of energy expenditures. Unfortunately, the standard errors are too large to allow for a conclusive statistical comparison. Finally, Panel F shows the employment responses. Consistent with theory, employment rises substantially more in nondurable goods industries. ${ }^{15}$

For the interpretation of the impulse responses in the impact period note that military spending by industry is constructed by aggregating the value of all contracts in a given year. I use the date on which the contract is signed for this aggregation. My dataset has no information on the date of actual payments. Panels B to F all suggest that there is little effect at the time the contract is signed, but only in subsequent years.

Taken together, nondurable goods industries respond strongly to increased defense spending while the reaction of durable goods industries is quite moderate. These findings are consistent with the theory described above, suggesting that indeed there is little crowding out in nondurable goods industries but substantial crowding out in durables industries.

\footnotetext{
${ }^{14}$ Value added and cost of materials roughly sum to gross output.

${ }^{15}$ I report estimates of impulse response functions for prices in Appendix C.5
} 
Figure 3: Impulse response functions for durable and nondurable goods
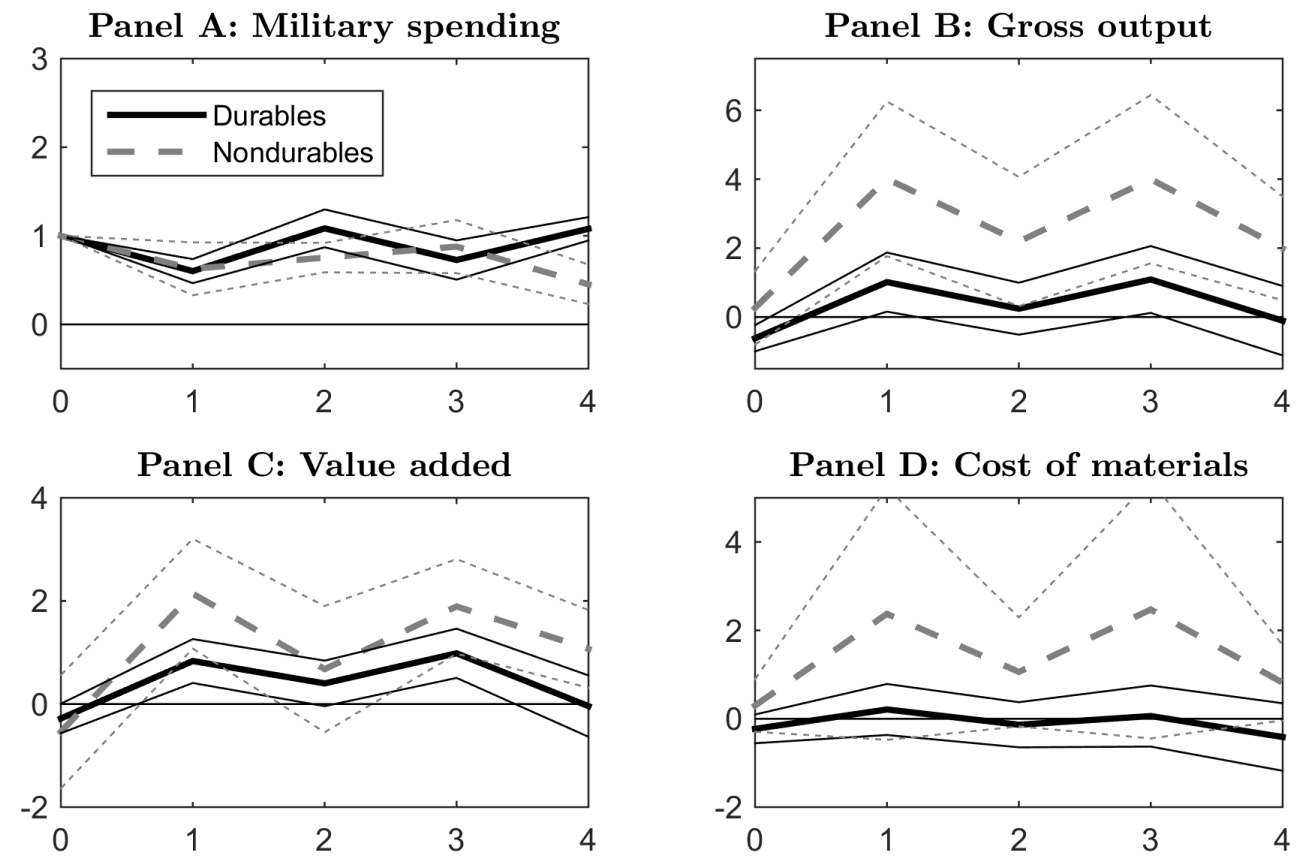

Panel D: Cost of materials

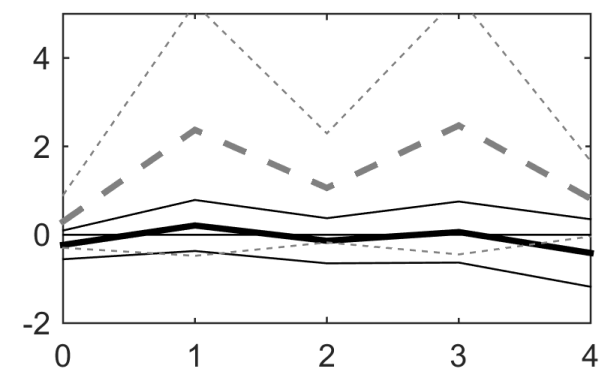

Panel E: Energy expenditures

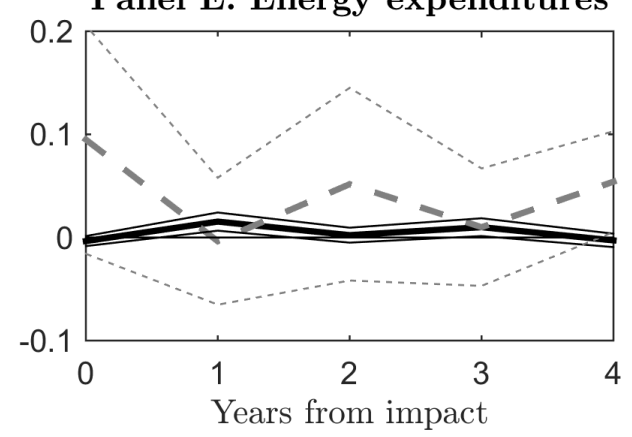

Panel F: Employment

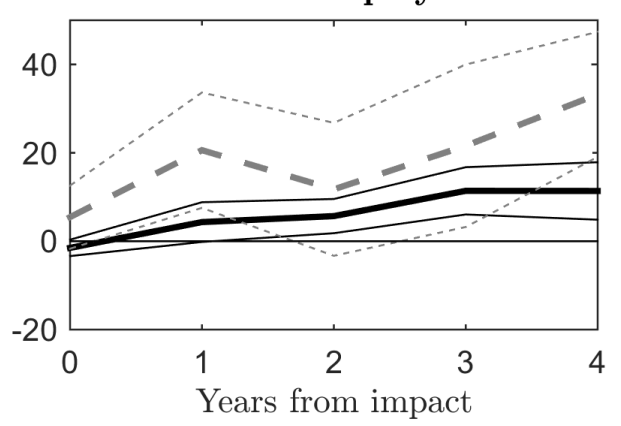

Notes: The figure plots impulse response functions for the baseline sample estimated using specification (20). See text for a description of the baseline sample. The shock is a unit increase of government spending above trend, normalized by the industry's value added. For production employment the impulse is a $\$ 1$ million increase in military spending and the response is expressed as the number of additional employees. Shaded regions mark 80 percent confidence bands based on standard errors that are clustered at the industry level.

I next compute the sectoral multipliers as the cumulative change in the outcome variable divided by the cumulative change in spending. Based on the model from the previous section and taking into account that military buildups typically have greater persistence than stabilizing interventions, I expect that the durables multiplier has about half the size of the nondurables multiplier.

Table 4 summarizes the estimated multipliers for time horizons of 1 to 3 years after the shock. 
The table confirms that multipliers for all five variables, gross output, value added, cost of materials, energy expenditures, and employment are uniformly larger in nondurable goods sectors. Notice that the employment multiplier is expressed as employees per year per $\$ 1$ million dollar of spending.

While most multipliers in Table 4 take empirically plausible sizes and are broadly in line with theoretical predictions, the gross output and cost of materials multipliers for nondurables are quite large. A likely explanation for this is that measurement problems give rise to upward biases. If firms in a particular industry use inputs from other firms in the same industry, shipments and cost of materials will be counted multiple times. The Use Tables of various years suggest that 10 percent is a conservative estimate of the share of intra-industry shipments. Under this assumption, one dollar of final sales is counted $1 /(1-0.1) \approx 1.11$ times. A similar problem arises from intra-firm, inter-plant shipments. ${ }^{16}$ For this reason it is preferable to compare industries on the basis of value added or employment. ${ }^{17}$

\section{Robustness}

I next discuss the robustness of these results. All estimates are reported in Appendix C.4.

One possible concern is that is that anticipation of future spending leads to asymmetric effects across industries which are not fully captured by time the fixed effects. To address this issue I add Ramey's (2011) defense news variable interacted with industry indicators to specification (20). The resulting multipliers are almost identical to those in the baseline specification (Table C5). A second concern may be that the time fixed effects do not fully control for monetary policy. The reason is that the interest sensitivity increases with the length of the service lives, and these vary across industries. When controlling for the real interest rate interacted with industry indicators, however, the results barely change (Table C6).

I next explore how the results depend on how the trend of the variables is extracted. For the baseline results I used an HP-filter with a smoothing parameter of 1600 . The estimates for the alternative smoothing parameters of 400 and 6000 are shown in Tables C7 and C8. For smaller values of the smoothing parameters the multipliers decrease slightly. Yet, there is not a single case in which a nondurables multiplier falls below the value of the corresponding durables multiplier.

\footnotetext{
${ }^{16}$ Atalay, Hortacsu, and Syverson (2014) report that 16 percent of shipments occur within the firm.

${ }^{17}$ See Chodorow-Reich et al. (2012), for instance, for estimates of employment multipliers.
} 
Table 4: Industry-level fiscal multipliers

\begin{tabular}{|c|c|c|c|}
\hline \multicolumn{4}{|c|}{ Durable goods multipliers } \\
\hline Years after shock & 1 & 2 & 3 \\
\hline Gross output & $\begin{array}{c}0.25 \\
{[-0.56,1.14]}\end{array}$ & $\begin{array}{c}0.24 \\
{[-0.46,1.18]}\end{array}$ & $\begin{array}{c}0.51 \\
{[-0.22,1.52]}\end{array}$ \\
\hline Value added & $\begin{array}{c}0.35 \\
{[-0.07,0.75]}\end{array}$ & $\begin{array}{c}0.36 \\
{[0.00,0.77]}\end{array}$ & $\begin{array}{c}0.57 \\
{[0.19,1.02]}\end{array}$ \\
\hline Cost of materials & {$\left[\begin{array}{c}-0.01 \\
{[-0.54,0.68]}\end{array}\right.$} & $\begin{array}{c}-0.06 \\
{[-0.52,0.66]}\end{array}$ & $\begin{array}{c}-0.03 \\
{[-0.45,0.76]}\end{array}$ \\
\hline Energy expenditures & $\begin{array}{c}0.007 \\
{[-0.005,0.013]}\end{array}$ & $\begin{array}{c}0.005 \\
{[-0.004,0.011]}\end{array}$ & $\begin{array}{c}0.007 \\
{[-0.002,0.014]}\end{array}$ \\
\hline $\begin{array}{l}\text { Employment } \\
\text { (employees per year per } \$ 1 \mathrm{~m})\end{array}$ & $\begin{array}{c}1.76 \\
{[-3.86,4.24]}\end{array}$ & $\begin{array}{c}3.17 \\
{[-1.24,6.19]}\end{array}$ & $\begin{array}{c}5.83 \\
{[1.51,9.29]}\end{array}$ \\
\hline \multicolumn{4}{|c|}{ Nondurable goods multipliers } \\
\hline Years after shock & 1 & 2 & 3 \\
\hline Gross output & $\begin{array}{c}2.63 \\
{[0.47,5.47]}\end{array}$ & $\begin{array}{c}2.72 \\
{[0.12,5.45]}\end{array}$ & $\begin{array}{c}3.21 \\
{[0.46,6.60]}\end{array}$ \\
\hline Value added & $\begin{array}{c}0.99 \\
{[0.05,2.58]}\end{array}$ & $\begin{array}{c}0.96 \\
{[-0.27,2.33]}\end{array}$ & $\begin{array}{c}1.28 \\
{[0.00,2.88]}\end{array}$ \\
\hline Cost of materials & $\begin{array}{c}1.64 \\
{[-0.58,4.68]}\end{array}$ & $\begin{array}{c}1.57 \\
{[-1.04,4.51]}\end{array}$ & $\begin{array}{c}1.90 \\
{[-0.88,5.54]}\end{array}$ \\
\hline Energy expenditures & $\begin{array}{c}0.056 \\
{[-0.014,0.114]}\end{array}$ & $\begin{array}{c}0.060 \\
{[-0.011,0.140]}\end{array}$ & $\begin{array}{c}0.047 \\
{[-0.021,0.110]}\end{array}$ \\
\hline $\begin{array}{l}\text { Employment } \\
\text { (employees per year per } \$ 1 \mathrm{~m} \text { ) }\end{array}$ & $\begin{array}{c}16.01 \\
{[5.26,33.64]}\end{array}$ & $\begin{array}{c}15.87 \\
{[1.47,31.21]}\end{array}$ & $\begin{array}{c}18.22 \\
{[3.19,33.32]}\end{array}$ \\
\hline
\end{tabular}

Notes: The table reports the cumulative multipliers for various outcome variables. Multipliers for gross output, value added, cost of materials, and energy expenditures have the usual interpretation of one additional dollar in the outcome variable per additional dollar of military spending. The multiplier for employment is expressed as the number of employees per year per $\$ 1$ million of military spending. 80 percent confidence intervals are reported in square brackets. They are calculated using a blocks-of-blocks bootstrap (see Berkowitz, Biegean, and Kilian (1999) and the references cited therein) with 2000 bootstrap samples.

Finally, I estimate durables multipliers at the 3-digit SIC level. ${ }^{18}$ This wider industry definition

\footnotetext{
${ }^{18}$ The sample size for nondurables industries is too small to obtain informative estimates.
} 
captures that spending on goods in one 4-digit industry may drive up prices of factors that are used in other 4-digit industries under the same 3-digit umbrella. As a result, one would expect larger crowding-out effects. Indeed, the durables multipliers at the 3-digit level are very close to zero (Table C9).

\subsubsection{The state of the business cycle}

Several studies have argued that the fiscal multiplier is larger in slumps than in booms (e.g. Auerbach and Gorodnichenko, 2012, 2013, Michaillat, 2014). To see whether this form of state dependence applies to the durable goods multiplier, I estimate impulse response functions separately for slack and nonslack periods (which I somewhat imprecisely refer to as recessions and expansions). I adopt a specification similar to Auerbach and Gorodnichenko (2013),

$$
\begin{aligned}
\frac{Y_{i, t+h}-Y_{i, t-1}^{T}}{V A_{i, t-1}^{T}}= & \alpha_{h}^{R} F_{i, t-1} \frac{G_{i, t}-G_{i, t-1}^{T}}{V A_{i, t-1}^{T}}+\alpha_{h}^{E}\left(1-F_{i, t-1}\right) \frac{G_{i, t}-G_{i, t-1}^{T}}{V A_{i, t-1}^{T}} \\
& +\sum_{k=1}^{2} \beta_{h, k}^{R} F_{i, t-1} \frac{Y_{i, t-k}-Y_{i, t-k-1}^{T}}{V A_{i, t-k-1}^{T}}+\sum_{k=1}^{2} \beta_{h, k}^{E}\left(1-F_{i, t-1}\right) \frac{Y_{i, t-k}-Y_{i, t-k-1}^{T}}{V A_{i, t-k-1}^{T}} \\
& +\sum_{k=1}^{2} \gamma_{h, k}^{R} F_{i, t-1} \frac{G_{i, t-k}-G_{i, t-k-1}^{T}}{V A_{i, t-k-1}^{T}}+\sum_{k=1}^{2} \gamma_{h, k}^{E}\left(1-F_{i, t-1}\right) \frac{G_{i, t-k}-G_{i, t-k-1}^{T}}{V A_{i, t-k-1}^{T}} \\
& +\eta_{h} F_{i, t-1}+\delta_{i, h}+\zeta_{t, h}+\varepsilon_{i, t+h} .
\end{aligned}
$$

In this equation

$$
F_{i, t}=\frac{\exp \left(-\kappa \cdot V A_{i, t}^{C}\right)}{1+\exp \left(-\kappa \cdot V A_{i, t}^{C}\right)}, \kappa>0,
$$

and $V A_{i, t}^{C}$ denotes the demeaned and standardized cycle component of value added in sector $i$. I use the one-sided HP-filter from Stock and Watson (1999) with a smoothing parameter of 1600 to extract the cycle component. ${ }^{1920} F_{i, t}$ measures the "degree" to which industry $i$ 's value added is below trend (in recession). It varies between zero and one and takes greater values whenever the industry's value added is low. Hence, the empirical model (22) permits estimation of impulse response functions separately for recessions $\left(F_{i, t}=1\right)$ and expansions $\left(F_{i, t}=0\right)$. These impulse response functions are given by $\left\{\alpha_{h}^{R}\right\}_{h=0}^{4}$ and $\left\{\alpha_{h}^{E}\right\}_{h=0}^{4}$. Parameter $\kappa$ is set to 1.5 which implies

\footnotetext{
${ }^{19}$ I would like to thank Valerie Ramey and Simon Gilchrist for pointing out to me that it is critical to use a one-sided filter in this specification.

${ }^{2 \mathrm{C}}$ Meyer-Gohde (2010) provides an implementation of the one-sided HP-filter by Stock and Watson (1999).
} 
that the economy spends about 20 percent of the time in recessions, a value consistent with U.S. business cycle facts. For more details see Auerbach and Gorodnichenko (2012, 2013). Notice, that I include $F_{i, t-1}$ as a control variable. By doing so, I allow the left-hand side variable to directly depend on the state of the economy. To address endogeneity concerns, I construct instruments by multiplying (21) with $F_{i, t-1}$ and $1-F_{i, t-1}$. The instruments are strong as the Angrist-Pischke F-statistics in Table show.

Figure 4 shows the impulse response functions starting with military spending in Panel A. A spending shock in recessions is followed by somewhat lower subsequent spending than a shock in expansions. There is little evidence for greater multipliers in recessions. The impulse response functions for gross output (Panel B), value added (Panel C), and cost of materials (Panel D) are initially negative in recessions and only gradually rise above zero. In expansions, these variables are positive at first and then return to values near zero. There is little information in the dynamic responses of energy expenditures (Panel E). Employment increases slightly after a fiscal shock in recessions, but after three years the impulse response function falls below the response in expansions (Panel F).

Table 5 shows the associated multipliers. They are often negative in recessions. Since the standard errors are large, this analysis cannot rule out that the durables fiscal multiplier depends on the state of the economy. Yet, it is unlikely that the degree of state dependence is sufficiently strong to render the durable goods multiplier "large" in recessions. ${ }^{21}$

\section{The zero lower bound}

In this section I return to theory and analyze the sizes of durables and nondurables multipliers in an economy in which the zero lower bound (ZLB) on the nominal interest rate binds. As I showed in Section 2.3.1, for very low depreciation rates the multiplier for durable goods is small regardless of the monetary policy response. For moderate depreciation rates, however, the multiplier can be larger when the ZLB binds.

To study government spending at the ZLB, I modify the model from Section 2 in two ways.

\footnotetext{
${ }^{21}$ Berger and Vavra (2014) argue that the durable goods fiscal multiplier is smaller in recessions than in expansions.
} 
Figure 4: Impulse response functions for durable goods in recessions and expansions
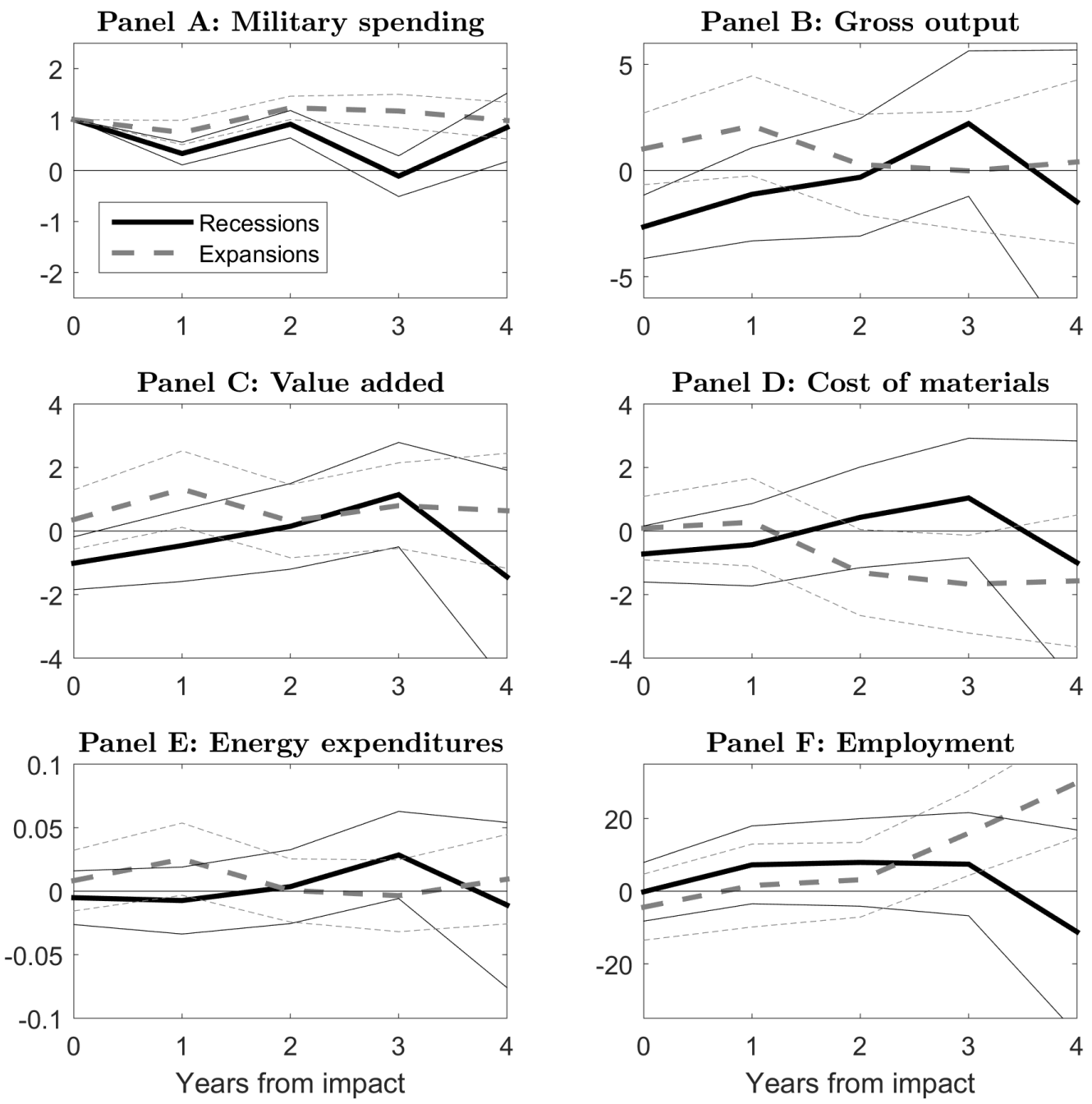

Notes: The figure plots impulse response functions for the durable goods industries of the baseline sample estimated using specification (22). See Section 3 for a description of the baseline sample. The shock is a unit increase of government spending above trend, normalized by the sector's value added. For employment the impulse is a $\$ 1$ million increase in military spending and the response is expressed as the number of additional employees. Shaded regions mark 80 percent confidence bands based on standard errors that are clustered at the industry level.

First, I replace the monetary policy rule (13) with

$$
i_{t}=\max \left\{0, \beta^{-1}-1+\phi_{\pi} \pi_{t}+\phi_{Y} \tilde{Y}_{t}\right\}
$$


Table 5: Industry-level multipliers for durable goods in recessions and expansions

\begin{tabular}{|c|c|c|c|}
\hline \multicolumn{4}{|c|}{ Recession multipliers } \\
\hline Years after shock & 1 & 2 & 3 \\
\hline Gross output & {$\left[\begin{array}{c}-2.82 \\
{[-8.04,0.81]}\end{array}\right.$} & {$[-6.42,1.05]$} & $\begin{array}{c}-0.87 \\
{[-3.83,3.26]}\end{array}$ \\
\hline Value added & {$\left[\begin{array}{l}-1.10 \\
{[-3.15,0.41]}\end{array}\right.$} & {$[-0.59$} & $\begin{array}{c}-0.08 \\
{[-2.26,1.38]}\end{array}$ \\
\hline Cost of materials & $\begin{array}{c}-0.87 \\
{[-3.17,1.33]}\end{array}$ & {$\left[\begin{array}{c}-0.32 \\
{[-2.36,1.66]}\end{array}\right.$} & $\begin{array}{c}0.15 \\
{[-2.36,2.73]}\end{array}$ \\
\hline Energy expenditures & $\begin{array}{c}-0.009 \\
{[-0.052,0.027]}\end{array}$ & $\begin{array}{c}-0.004 \\
{[-0.037,0.032]}\end{array}$ & $\begin{array}{c}0.009 \\
{[-0.052,0.053]}\end{array}$ \\
\hline $\begin{array}{l}\text { Employment } \\
\text { (employees per year per } \$ 1 \mathrm{~m})\end{array}$ & $\begin{array}{c}5.33 \\
{[-10.38,23.64]}\end{array}$ & $\begin{array}{c}6.70 \\
{[-6.16,26.53]}\end{array}$ & $\begin{array}{c}10.53 \\
{[-16.82,31.20]}\end{array}$ \\
\hline \multicolumn{4}{|c|}{ Expansion multipliers } \\
\hline Years after shock & 1 & 2 & 3 \\
\hline Gross output & $\begin{array}{c}1.79 \\
{[-0.60,3.81]}\end{array}$ & $\begin{array}{c}1.15 \\
{[-0.93,3.14]}\end{array}$ & $\begin{array}{c}0.82 \\
{[-1.36,2.76]}\end{array}$ \\
\hline Value added & $\begin{array}{c}0.96 \\
{[-0.27,2.02]}\end{array}$ & $\begin{array}{c}0.67 \\
{[-0.27,1.74]}\end{array}$ & $\begin{array}{c}0.67 \\
{[-0.44,1.67]}\end{array}$ \\
\hline Cost of materials & $\begin{array}{c}0.21 \\
{[-1.78,1.79]}\end{array}$ & $\begin{array}{c}-0.32 \\
{[-1.87,1.34]}\end{array}$ & $\begin{array}{c}-0.63 \\
{[-1.90,1.20]}\end{array}$ \\
\hline Energy expenditures & $\begin{array}{c}0.019 \\
{[-0.016,0.042]}\end{array}$ & $\begin{array}{c}0.011 \\
{[-0.015,0.030]}\end{array}$ & $\begin{array}{c}0.007 \\
{[-0.020,0.022]}\end{array}$ \\
\hline $\begin{array}{l}\text { Employment } \\
\text { (employees per year per } \$ 1 \mathrm{~m})\end{array}$ & $\begin{array}{c}-1.63 \\
{[-17.75,5.46]}\end{array}$ & $\begin{array}{c}0.10 \\
{[-13.70,5.94]}\end{array}$ & $\begin{array}{c}3.93 \\
{[-9.25,9.45]}\end{array}$ \\
\hline
\end{tabular}

Notes: The table reports the cumulative multipliers for various outcome variables. Multipliers for gross output, value added, cost of materials, and energy expenditures have the usual interpretation of one additional dollar in the outcome variable per additional dollar of military spending. The multiplier for employment is expressed as the number of employees per year per $\$ 1$ million of military spending. 80 percent confidence intervals are reported in square brackets. They are calculated using a blocks-of-blocks bootstrap (see Berkowitz, Biegean, and Kilian (1999) and the references cited therein) with 2000 bootstrap samples.

where $\phi_{\pi}=1.1$ and $\phi_{Y}=0$. Second, I assume that the discount factor follows the AR(1) process

$$
\beta_{t}=\left(1-\varrho_{\beta}\right) \beta+\varrho_{\beta} \beta_{t-1}+\varepsilon_{\beta, t} .
$$


The remaining model equations and the calibration remain unchanged.

I consider the following scenario. Prior to time 0, the economy is subject to a positive discount factor shock so that the ZLB begins to bind. The government then raises spending on $X$ by 100 (artificial) quantity units at time 0 . I choose the persistence of the discount factor shock $\varrho_{\beta}$ to imply that the ZLB continues to bind for 4, 8, and 16 quarters beginning at time 0 . The persistence of the spending shock is as in the baseline calibration, $\varrho_{X}=0.75$. I assume that the government spending shock is sufficiently small to never lift the economy out of the ZLB regime. The fiscal multiplier is then computed from the incremental output response to the shock in government spending. ${ }^{22}$

Figure 5 shows the multipliers together with the impulse response functions of the price level $P$. When the ZLB binds for 4 quarters (Panels A and B), the multiplier for nondurable goods is slightly below 2. The multiplier is smaller when the government purchases goods with greater durability. For durables with 10 year service lives the multiplier is below unity and for durables with 80 year service lives the multiplier is below 0.3 . Hence, for a short period of 4 quarters at the ZLB the ordering of multipliers remains unchanged, but they are larger than when the central bank offsets the expansion by raising the interest rate.

At the ZLB greater government spending raises inflation and thereby lowers real interest rates. Lower real rates, in turn, crowd in private sector spending. Hence, to understand the size of the fiscal multiplier at the ZLB, it is crucial to understand the inflation response to government spending - and this inflation response is quite different for durable and nondurable goods. As can be seen in Panel B, government spending on nondurable goods raises inflation substantially more than spending on durable goods. Additionally, the impulse response for nondurable goods displays a slightly hump-shaped pattern with initial inflation and subsequent mild deflation as the government reduces spending. When good $X$ is durable, inflation continues to rise for much longer, reflecting the fact that households rebuild their durables stock as soon as government demand falls.

For the fiscal multiplier to be large, inflation must be high when the interest rate is fixed at the ZLB. Conversely, deflation at the ZLB has strong contractionary effects. Panels C and D show the multiplier and the price path when the ZLB binds for 8 quarters. The multiplier for the moderately durable good with a service life of 10 years is now above one and the nondurables multiplier is near

\footnotetext{
${ }^{22}$ More precisely, the impulse response functions are computed as the difference between the response with the fiscal policy shock and that without the fiscal policy shock. The resulting price dynamics are therefore entirely caused by the spending and not the discount factor shock.
} 
Figure 5: Model impulse response functions

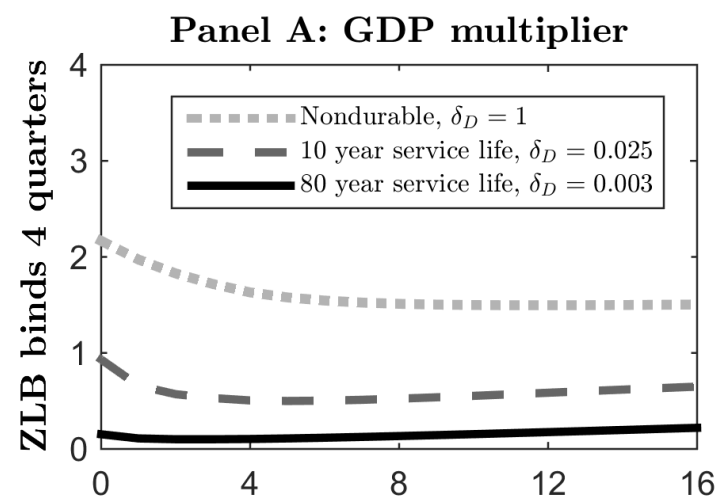

Panel B: Price level P

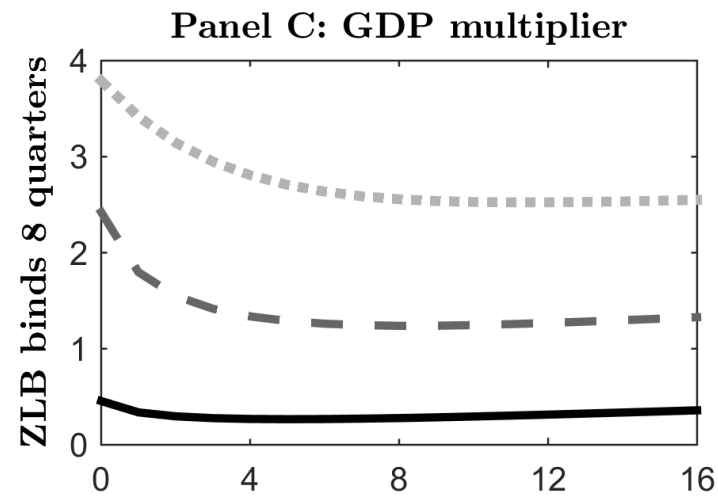

Panel D: Price level P

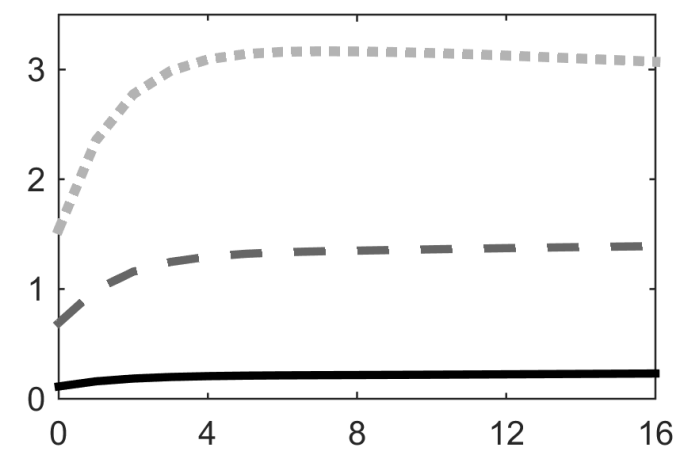

Panel E: GDP multiplier

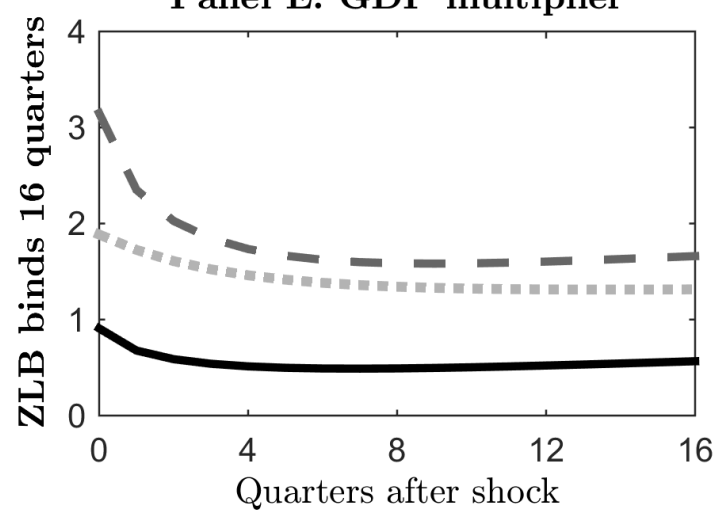

Panel F: Price level $\mathbf{P}$

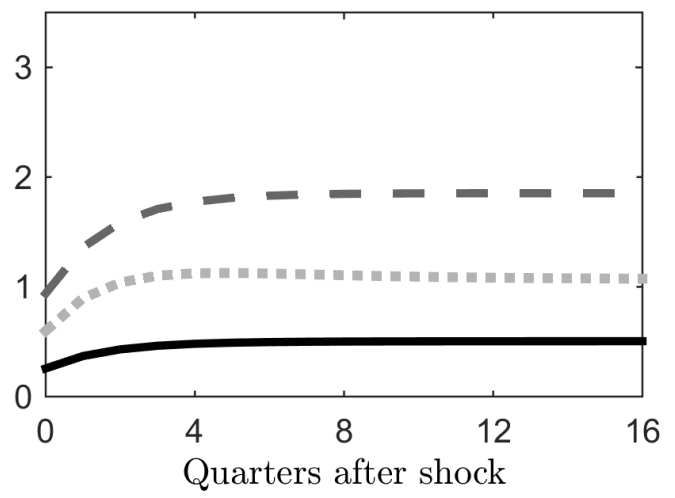

Notes: The figure fiscal multipliers and impulse response functions for various depreciation rates. Prior to time 0, the household's discount factor is first shocked so that the ZLB begins to bind. The persistence of the shock is chosen to imply that the ZLB binds for 4, 8, and 16 quarters beginning at time 0 . At time 0 the government raises spending on $X$ by 100 basis points. The impulse response functions for prices are expressed in relative deviations from steady state and the units are basis points. 
3.

The multiplier for nondurables falls when the ZLB binds for 16 quarters (Panel E). The reason is that prices are falling while the economy is at the ZLB. In fact, when the ZLB binds for 16 quarters, the multiplier for nondurables falls below that for moderately durable goods with $\delta_{D}=0.025$. The catch-up of private sector spending prevents inflation from falling as much as it does when the government purchases nondurable goods. For the long-lived durable the multiplier remains below one.

In summary, the multiplier remains relatively small at the ZLB when the good in question is sufficiently durable. Yet, for goods with intermediate durability the multiplier can be above one if the ZLB binds sufficiently long.

\section{Conclusion}

Both neoclassical and New Keynesian models predict that the fiscal multiplier for temporary increases in spending is much smaller when the government buys durable rather than nondurable goods. I show that empirical evidence confirms this prediction. In U.S. aggregate data the fiscal multiplier is about 0.5 smaller if the government purchases durable rather than nondurable goods. At the industry level, spending in durables industries also leads to substantially smaller increases in economic activity than spending in nondurables industries.

These results raise significant concerns about the effectiveness of fiscal stimulus that is targeted towards infrastructure. As many other stimulus programs, the American Recovery and Reinvestment Act contained provisions to raise spending on highly durable goods such as highway infrastructure, high-speed rail corridors, railroads, airports, and broadband. ${ }^{23}$ More generally, it has been suggested to assemble a pool of "shovel-ready projects" to be implemented when the economy next plunges into recession. The findings in this paper suggest that such policies are unlikely to have substantial effects on aggregate demand.

This paper also provides guidance for future research on fiscal policy. The large difference in the sizes of durables and nondurables multipliers imply that future work should distinguish between these types of spending. Since the composition of spending matters, estimates of multipliers for

\footnotetext{
${ }^{23}$ This information is taken from http://www.recovery.gov/arra/Transparency/fundingoverview/Pages/ fundingbreakdown.aspx. Since the website is not operated anymore, I accessed a cached version (from 01/04/2014) via https://archive.org/
} 
total spending suffer from an external validity problem. If the composition of spending changes, the multiplier changes as well.

Finally, it is likely that other product dimensions matter. As a general rule, industries with more elastic supply curves and less elastic demand curves should have larger fiscal multipliers. Price stickiness, factor mobility, and tradability are just three properties likely to be associated with the elasticities of demand or supply. 


\section{References}

Adda, Jerome and Russell Cooper. 2000. "Balladurette and Juppette: A Discrete Analysis of Scrapping Subsidies." Journal of Political Economy 108 (4):778-806.

Aschauer, David Alan. 1989. "Is public expenditure productive?" Journal of Monetary Economics 23 (2):177-200.

Atalay, Enghin, Ali Hortacsu, and Chad Syverson. 2014. "Vertical Integration and Input Flows." American Economic Review 104 (4):1120-48.

Auerbach, Alan J. and Yuriy Gorodnichenko. 2012. "Measuring the Output Responses to Fiscal Policy." American Economic Journal: Economic Policy 4 (2):1-27.

. 2013. "Output Spillovers from Fiscal Policy." American Economic Review $103(3): 141-46$.

Bachmann, Ruediger and Eric R. Sims. 2012. "Confidence and the transmission of government spending shocks." Journal of Monetary Economics 59 (3):235-249.

Barro, Robert J. and Charles J. Redlick. 2011. "Macroeconomic Effects From Government Purchases and Taxes." The Quarterly Journal of Economics 126 (1):51-102.

Barsky, Robert, Christopher L. House, and Miles Kimball. 2003. "Do Flexible Durable Goods Prices Undermine Sticky Price Models?" NBER Working Papers, National Bureau of Economic Research, Inc.

Barsky, Robert B., Christopher L. House, and Miles S. Kimball. 2007. "Sticky-Price Models and Durable Goods." American Economic Review 97 (3):984-998.

Bartelsman, Eric J. and Wayne Gray. 1996. "The NBER Manufacturing Productivity Database." NBER Technical Working Papers, National Bureau of Economic Research, Inc.

Bartik, Timothy J. 1991. Who Benefits from State and Local Economic Development Policies? No. wbsle in Books from Upjohn Press. W.E. Upjohn Institute for Employment Research.

Baxter, Marianne and Robert G King. 1993. "Fiscal Policy in General Equilibrium." American Economic Review 83 (3):315-34.

Becker, Randy, Wayne Gray, and Jordan Marvakov. 2013. "NBER-CES Manufacturing Industry Database: Technical Notes." Technical Working Paper, .

Berger, David and Joseph Vavra. 2014. "Measuring How Fiscal Shocks Affect Durable Spending in Recessions and Expansions." American Economic Review 104 (5):112-15.

Berkowitz, Jeremy, Ionel Biegean, and Lutz Kilian. 1999. "On the finite-sample accuracy of nonparametric resampling algorithms for economic time series." Tech. rep. 
Bullard, James and Kaushik Mitra. 2002. "Learning about monetary policy rules." Journal of Monetary Economics 49 (6):1105-1129.

Bureau of Economic Analysis. undated. "BEA Depreciation Estimates." , Bureau of Economic Analysis. URL http://www.bea.gov/national/pdf/BEA_depreciation_rates. pdf.

Calvo, Guillermo A. 1983. "Staggered prices in a utility-maximizing framework." Journal of Monetary Economics 12 (3):383-398.

Cashin, David and Takashi Unayama. 2012. "Short-run Distributional Effects of VAT Rate Change: Evidence from a consumption tax rate increase in Japan." Discussion papers, Research Institute of Economy, Trade and Industry (RIETI).

Chetty, Raj, Adam Guren, Day Manoli, and Andrea Weber. 2011. "Are Micro and Macro Labor Supply Elasticities Consistent? A Review of Evidence on the Intensive and Extensive Margins." American Economic Review 101 (3):471-75.

Chodorow-Reich, Gabriel, Laura Feiveson, Zachary Liscow, and William Gui Woolston. 2012. "Does State Fiscal Relief during Recessions Increase Employment? Evidence from the American Recovery and Reinvestment Act." American Economic Journal: Economic Policy 4 (3):118-45.

Christiano, Lawrence, Martin Eichenbaum, and Sergio Rebelo. 2011. "When Is the Government Spending Multiplier Large?" Journal of Political Economy 119 (1):78 - 121.

Eberly, Janice, Sergio Rebelo, and Nicolas Vincent. 2008. "Investment and Value: A Neoclassical Benchmark." NBER Working Papers, National Bureau of Economic Research, Inc.

Erceg, Christopher and Andrew Levin. 2006. "Optimal monetary policy with durable consumption goods." Journal of Monetary Economics 53 (7):1341-1359.

Farhi, Emmanuel and Ivan Werning. 2012. "Fiscal Multipliers: Liquidity Traps and Currency Unions." NBER Working Papers, National Bureau of Economic Research, Inc.

Finn, Mary G. 1998. "Cyclical Effects of Government's Employment and Goods Purchases." International Economic Review 39 (3):635-57.

Gali, Jordi. 2008. Monetary Policy, Inflation and the Business Cycle: An Introduction to the New Keynesian Framework. Princeton University Press, Princeton NJ.

Hall, Robert E. 1988. "Intertemporal Substitution in Consumption." Journal of Political Economy 96 (2):339-57.

Hall, Robert E. 2009. "By How Much Does GDP Rise If the Government Buys More Output?" Brookings Papers on Economic Activity 40 (2 (Fall)):183-249.

Hausman, Joshua. 2015. "What was Bad for GM was Bad for America: The Auto Industry and the 1937-38 Recession." Working paper, University of Michigan. 
House, Christopher L. 2009. "Comment on: By How Much Does GDP Rise If the Government Buys More Output?" Brookings Papers on Economic Activity 40 (2 (Fall)):236-244.

House, Christopher L. and Matthew D. Shapiro. 2008. "Temporary Investment Tax Incentives: Theory with Evidence from Bonus Depreciation." American Economic Review 98 (3):737-68.

Kimball, Miles S. and Matthew D. Shapiro. 2008. "Labor Supply: Are the Income and Substitution Effects Both Large or Both Small?" Nber working papers, National Bureau of Economic Research, Inc.

Leduc, Sylvain and Daniel Wilson. 2013. "Roads to Prosperity or Bridges to Nowhere? Theory and Evidence on the Impact of Public Infrastructure Investment." NBER Macroeconomics Annual 27 (1):89 - 142.

Mankiw, N Gregory. 1985. "Consumer Durables and the Real Interest Rate." The Review of Economics and Statistics 67 (3):353-62.

Meyer-Gohde, Alexander. 2010. "Matlab code for one-sided HP-filters."

Mian, Atif and Amir Sufi. 2012. "The Effects of Fiscal Stimulus: Evidence from the 2009 Cash for Clunkers Program." The Quarterly Journal of Economics 127 (3):1107-1142.

Michaillat, Pascal. 2014. "A Theory of Countercyclical Government Multiplier." American Economic Journal: Macroeconomics 6 (1):190-217.

Nakamura, Emi and Jon Steinsson. 2014. "Fiscal Stimulus in a Monetary Union: Evidence from US Regions." American Economic Review 104 (3):753-92.

Nekarda, Christopher J. and Valerie A. Ramey. 2011. "Industry Evidence on the Effects of Government Spending." American Economic Journal: Macroeconomics 3 (1):36-59.

Òscar Jordà. 2005. "Estimation and Inference of Impulse Responses by Local Projections." American Economic Review 95 (1):161-182.

Owyang, Michael T., Valerie A. Ramey, and Sarah Zubairy. 2013. "Are Government Spending Multipliers Greater during Periods of Slack? Evidence from Twentieth-Century Historical Data." American Economic Review 103 (3):129-34.

Pappa, Evi. 2009a. "The effects of fiscal expansions: an international comparison." Working Paper, Barcelona Graduate School of Economics.

- 2009b. "The Effects Of Fiscal Shocks On Employment And The Real Wage." International Economic Review 50 (1):217-244.

Pereira, Alfredo M. 2000. "Is All Public Capital Created Equal?" The Review of Economics and Statistics $82(3): 513-518$.

Perotti, Roberto. 2004. "Public investment: another (different) look." Working Paper, Bocconi University. 
Ramey, Valerie A. 2011. "Identifying Government Spending Shocks: It's all in the Timing." The Quarterly Journal of Economics 126 (1):1-50.

Ramey, Valerie A. and Matthew D. Shapiro. 1998. "Costly capital reallocation and the effects of government spending." Carnegie-Rochester Conference Series on Public Policy 48 (1):145-194.

Ravn, Morten O. and Harald Uhlig. 2002. "On adjusting the Hodrick-Prescott filter for the frequency of observations." The Review of Economics and Statistics 84 (2):371-375.

Rendahl, Pontus. 2014. "Fiscal Policy in an Unemployment Crisis." Discussion papers, Centre for Macroeconomics (CFM).

Stock, James H. and Mark W. Watson. 1999. "Forecasting inflation." Journal of Monetary Economics 44 (2):293-335.

Woodford, Michael. 2011. "Simple Analytics of the Government Expenditure Multiplier." American Economic Journal: Macroeconomics 3 (1):1-35. 


\section{A Model appendix}

\section{A.1 Summary of equations}

In this part of the Appendix I summarize the equations of the most general model with adjustment costs and time-varying discount factor. $q_{X, t}$ and $q_{Z, t}$ denote the shadow values of one unit of capital in the two sectors. To obtain the model in Section 2 set $\beta_{t}=\beta$ and $\zeta_{K}=0$.

The household's behavior is summarized the following equations:

$$
\begin{gathered}
\lambda_{t}=\left(1+i_{t}\right) \mathbb{E}_{t}\left[\beta_{t+1} \lambda_{t+1}\right] \\
\frac{\partial v\left(N_{Z, t}, N_{X, t}\right)}{\partial N_{j, t}}=\lambda_{t} W_{j, t}, j \in\{X, Z\} \\
\frac{\partial u\left(C_{t}, D_{H, t}\right)}{\partial C_{t}}=\lambda_{t} P_{Z, t} \\
q_{j, t}=\lambda_{t} P_{Z, t}\left(1+\zeta_{K}\left(\frac{I_{j, t}}{K_{j, t-1}}-\delta_{K}\right)\right), j \in\{X, Z\} \\
q_{j, t}=\mathbb{E}_{t}\left[\beta_{t+1} \lambda_{t+1} R_{j, t+1}+\beta_{t+1} \lambda_{t+1} P_{j, t+1} \frac{\zeta_{K}}{2}\left(\left(\frac{I_{j, t+1}}{K_{j, t}}\right)^{2}-\left(\delta_{K}\right)^{2}\right)+\beta_{t+1}\left(1-\delta_{K}\right) q_{j, t+1}\right], j \in\{X, Z\} \\
\gamma_{t}=\frac{\partial u\left(C_{t}, D_{H, t}\right)}{\partial D_{H, t}}+\left(1-\delta_{D}\right) \mathbb{E}_{t}\left[\beta_{t+1} \gamma_{t+1}\right]
\end{gathered}
$$

The accumulation equations (2) and equation (15) in the text continue to hold.

Firms' reset their prices according to

$$
p_{j, t}^{*}=\frac{\varepsilon}{\varepsilon-1} \frac{\mathbb{E}_{t} \sum_{k=0}^{\infty}\left(\theta_{j}\right)^{k} \lambda_{t+k} \prod_{s=1}^{k} \beta_{t+s}\left(P_{j, t+k}\right)^{\varepsilon} j_{t+k} M C_{j, t+k}}{\mathbb{E}_{t} \sum_{k=0}^{\infty}\left(\theta_{j}\right)^{k} \lambda_{t+k} \prod_{s=1}^{k} \beta_{t+s}\left(P_{j, t+k}\right)^{\varepsilon} j_{t+k}}, j \in\{X, Z\}
$$

and prices in both sectors evolve according to

$$
P_{j, t}=\left(\theta_{j}\left(P_{j, t-1}\right)^{1-\varepsilon}+\left(1-\theta_{j}\right)\left(p_{j, t}^{*}\right)^{1-\varepsilon}\right)^{\frac{1}{1-\varepsilon}}, j \in\{X, Z\} .
$$

Nominal marginal costs in the two sectors are

$$
\begin{gathered}
M C_{X, t}(s)=\left(\frac{P_{Z, t}}{1-\chi}\right)^{1-\chi}\left(\frac{R_{X, t}}{\alpha \chi}\right)^{\chi \alpha}\left(\frac{W_{X, t}}{(1-\alpha) \chi}\right)^{\chi(1-\alpha)}, \\
M C_{Z, t}(s)=\left(\frac{R_{Z, t}}{\alpha}\right)^{\alpha}\left(\frac{W_{Z, t}}{1-\alpha}\right)^{1-\alpha} .
\end{gathered}
$$


The conditional factor demand functions are

$$
\begin{gathered}
M_{X, t}=\left(\frac{P_{Z, t}}{1-\chi}\right)^{-\chi}\left(\frac{R_{X, t}}{\alpha \chi}\right)^{\chi \alpha}\left(\frac{W_{X, t}}{(1-\alpha) \chi}\right)^{\chi(1-\alpha)} X_{t} \\
K_{X, t-1}=\left(\frac{P_{Z, t}}{1-\chi}\right)^{1-\chi}\left(\frac{R_{X, t}}{\alpha \chi}\right)^{\chi \alpha-1}\left(\frac{W_{X, t}}{(1-\alpha) \chi}\right)^{\chi(1-\alpha)} X_{t} \\
N_{X, t}=\left(\frac{P_{Z, t}}{1-\chi}\right)^{1-\chi}\left(\frac{R_{X, t}}{\alpha \chi}\right)^{\chi \alpha}\left(\frac{W_{X, t}}{(1-\alpha) \chi}\right)^{\chi(1-\alpha)-1} X_{t} \\
K_{Z, t-1}=\left(\frac{R_{Z, t}}{\alpha}\right)^{\alpha-1}\left(\frac{W_{Z, t}}{1-\alpha}\right)^{1-\alpha} Z_{t} \\
N_{Z, t}=\left(\frac{R_{Z, t}}{\alpha}\right)^{\alpha}\left(\frac{W_{Z, t}}{1-\alpha}\right)^{-\alpha} Z_{t} .
\end{gathered}
$$

The market clearing condition in the $Z$ sector with capital adjustment costs is

$$
Z_{t}=C_{t}+I_{X, t}+I_{Z, t}+M_{X, t}+K_{X, t-1} \frac{\zeta_{K}}{2}\left(\frac{I_{X, t}}{K_{X, t-1}}-\delta_{K}\right)^{2}+K_{Z, t-1} \frac{\zeta_{K}}{2}\left(\frac{I_{Z, t}}{K_{Z, t-1}}-\delta_{K}\right)^{2} .
$$

Market clearing for the $X$ sector, accounting, government spending, and the monetary policy rule are as described in the text (equations 7 to 13).

\section{A.2 Proofs of approximation results}

In what follows the notation $\tilde{X}_{t}=\frac{X_{t}-X}{X}$ denotes the percentage deviation of variable $X_{t}$ from its steady state value. I prove the results for the case in which the fiscal policy shock has no persistence, $\varrho_{X}=0$, although they can be generalized to cases with mild persistence. I assume that prior to the shock the economy is in the steady state. Notice that the references in Appendix A.1 correspond to the baseline model in the text when there are no adjustment costs, $\zeta_{K}=0$, and the discount factor $\beta$ is constant.

\section{A.2.1 Spending on durable goods}

Approximation result 1. Suppose $\delta_{K}$ and $\delta_{D}$ are arbitrarily close to zero and $\beta$ is arbitrarily close to 1 . Then, for a short-lived increase in spending, it is approximately true that (1) $\Delta X_{H, t} \approx-\Delta X_{G, t}$, (2) the price $P_{X, t}$ remains unchanged, (3) the sectoral multipliers for gross output and value added are zero, $\frac{\mathrm{d} G O_{X, t}}{\mathrm{~d} G_{X, t}} \approx \frac{\mathrm{d} V A_{X, t}}{\mathrm{~d} G_{X, t}} \approx 0$, and (4) the aggregate multiplier is zero, $\frac{\mathrm{d} Y_{t}}{\mathrm{~d} G_{X, t}} \approx 0$.

Proof I first show that these assumptions imply that the stocks $K_{X, t}, K_{Z, t}$ and $D_{H, t}$ are approximately constant. The linear approximation of the accumulation equation for 
durables (equation 2) is

$$
\tilde{D}_{H, t}=\delta_{D} \tilde{X}_{H, t}+\left(1-\delta_{D}\right) \tilde{D}_{H, t-1}
$$

It then follows from the assumptions $\delta_{D} \rightarrow 0$ and $\tilde{D}_{H, t-1}=0$ that $\tilde{D}_{H, t} \approx 0$. Similarly, $\tilde{K}_{X, t} \approx \tilde{K}_{Z, t} \approx 0$.

The respective shadow values $\gamma_{t}, q_{X, t}, q_{Z, t}$ are also approximately constant under these assumptions. This can be seen using the linear approximation of equation (A6),

$$
\tilde{\gamma}_{t}=-\frac{\left(1-\left(1-\delta_{D}\right) \beta\right)}{\sigma_{D}} \tilde{D}_{H, t}+\frac{\left(1-\left(1-\delta_{D}\right) \beta\right)}{\sigma_{D C}} \tilde{C}_{t}+\left(1-\delta_{D}\right) \beta \mathbb{E}_{t}\left[\tilde{\gamma}_{t+1}\right]
$$

Here, $\sigma_{D}$ and $\sigma_{D C}$ are constants. Clearly, under the assumptions $\delta_{D} \rightarrow 0$ and $\beta \rightarrow 1$ it follows that $\tilde{\gamma}_{t} \approx \mathbb{E}_{t}\left[\tilde{\gamma}_{t+1}\right]$. Since this variable is stationary and returns to its steady state value eventually it must be that $\tilde{\gamma}_{t} \approx 0$. Similarly, $q_{X, t} \approx q_{Z, t} \approx 0$.

I next guess that $\tilde{P}_{X, t}=0$. It then follows from equations (15) and (A4) that $\tilde{\lambda}_{t}=0$ and $\tilde{P}_{Z, t}=0$. This guess, together with $\tilde{D}_{H, t} \approx \tilde{K}_{X, t} \approx \tilde{K}_{Z, t} \approx 0$ and the assumption that $\varrho_{X}=0$ implies that all state variables from period $t+1$ onwards are zero. Hence all other variables from period $t+1$ onwards are zero.

With these results in hand it is easy to show that

$$
\Delta X_{H, t}=-\Delta X_{G, t}
$$

$\Delta I_{X, t}+\Delta I_{Z, t}=0$ and that no other variable at time $t$ responds to the fiscal policy shock. Notice that since neither of the prices adjust nor the quantities $X_{t}, Z_{t}$ or $Y_{t}$ change, the monetary policy rule (13) implies that the nominal interest rate remains unchanged. The claims on the multipliers now follow immediately.

\section{A.2.2 Spending on nondurable goods}

Approximation result 2. Suppose $\delta_{D}=1, \delta_{K}$ is arbitrarily close to zero and $\beta$ is arbitrarily close to 1. Suppose further that $\theta_{X}=\theta_{Z}=0$, that is, prices are fully flexible, and that $u_{C D}=v_{X Z}=0$. Lastly, assume that the government subsidizes monopolistic firms such that $\frac{P_{Z} M_{X}}{P_{X} X}=1-\chi$. Next, define

$$
\sigma_{D}=-\frac{u_{D}\left(C, D_{H}\right)}{D_{H} u_{D D}\left(C, D_{H}\right)} \text { and } \eta_{X}=\frac{v_{X}\left(N_{Z}, N_{X}\right)}{N_{X} v_{X X}\left(N_{Z}, N_{X}\right)} .
$$

Then a short-lived increase in spending yields a gross output sectoral multiplier equal to

$$
\frac{\mathrm{d} G O_{X, t}}{\mathrm{~d} G_{X, t}} \approx \frac{\left(1+\eta_{X}^{-1}\right) \chi^{-1}-\left(\alpha+\eta_{X}^{-1}\right)}{\sigma_{D}\left(\alpha+\eta_{X}^{-1}\right) \frac{X_{H}}{X}+\left(1+\eta_{X}^{-1}\right) \chi^{-1}-\left(\alpha+\eta_{X}^{-1}\right)}
$$


and approximately equal sectoral value added and aggregate multipliers

$$
\frac{\mathrm{d} V A_{X, t}}{\mathrm{~d} G_{X, t}} \approx \frac{\mathrm{d} Y_{t}}{\mathrm{~d} G_{X, t}} \approx \frac{1-\alpha}{\sigma_{D}\left(\alpha+\eta_{X}^{-1}\right) \frac{X_{H}}{X}+\left(1+\eta_{X}^{-1}\right) \chi^{-1}-\left(\alpha+\eta_{X}^{-1}\right)} .
$$

The relative price $P_{X, t} / P_{Z, t}$ rises in response to greater spending.

Proof Similar to the proof in A.2.1, the assumptions that $\beta \rightarrow 1$ and $\delta_{K} \rightarrow 0$ implies that $\tilde{K}_{X, t} \approx \tilde{K}_{Z, t} \approx \tilde{q}_{Z, t} \approx \tilde{q}_{X, t} \approx 0$. It then immediately follows from (A4) that $\tilde{\lambda}_{t}=-\tilde{P}_{Z, t}$. Additionally, equation (15) implies that $\tilde{\gamma}_{t}=\tilde{P}_{X, t}-\tilde{P}_{Z, t}$, and (A3) implies that $\tilde{C}_{t}=0$. Using these relationships in the labor supply functions (A2) yields

$$
\frac{1}{\eta_{Z}} \tilde{N}_{Z, t}=\tilde{W}_{Z, t}-\tilde{P}_{Z, t} \text { and } \frac{1}{\eta_{X}} \tilde{N}_{X, t}=\tilde{W}_{X, t}-\tilde{P}_{Z, t}
$$

Additionally, the household's demand for good $X$ (equation A6) becomes

$$
\tilde{P}_{X, t}-\tilde{P}_{Z, t}=-\frac{1}{\sigma_{D}} \tilde{X}_{H, t}
$$

With these results in hand, it is straightforward but tedious to show that $\tilde{Z}_{t}=0$ and that

$$
\tilde{X}_{t}=\frac{\left(1+\eta_{X}^{-1}\right) \chi^{-1}-\left(\alpha+\eta_{X}^{-1}\right)}{\left(1-\chi \alpha+(1-\chi) \eta_{X}^{-1}\right) \chi^{-1}+\left(\alpha+\eta_{X}^{-1}\right) \sigma_{D} \frac{X_{H}}{X}} \frac{X_{G}}{X} \tilde{X}_{G, t}
$$

and

$$
\tilde{M}_{X, t}=\frac{\left(1+\eta_{X}^{-1}\right) \chi^{-1}}{\left(1-\chi \alpha+(1-\chi) \eta_{X}^{-1}\right) \chi^{-1}+\left(\alpha+\eta_{X}^{-1}\right) \sigma_{D} \frac{X_{H}}{X}} \frac{X_{G}}{X} \tilde{X}_{G, t}
$$

Recall the assumption that there is a subsidy that implies that $\frac{P_{Z} M_{X}}{P_{X} X}=1-\chi$. An advalorem subsidy of $\frac{1}{\varepsilon}$ on purchases of the intermediate is one way to ensure this relationship. Using the definitions of gross output, value added, and GDP, and the fact that $\frac{P_{Z} M_{X}}{P_{X} X}=1-\chi$ the results for the multipliers are now easily shown. Notice finally that $\tilde{P}_{X, t}-\tilde{P}_{Z, t}$ rises as $\tilde{X}_{H, t}$ falls (equation A17).

\section{A.3 Robustness of fiscal multipliers to alternative calibrations}

In this part of the appendix I check the robustness of the fiscal multipliers to alternative calibrations. The first three rows in Table A1 illustrate the role of capital adjustment costs. Whereas neither gross output nor value added sectoral multipliers change substantially with adjustment costs, aggregate multipliers do. Higher adjustment costs imply less crowding out of investment through purchases of intermediates. When adjustment costs are high, aggregate multipliers are quite close to the gross output multipliers.

I next relax the assumption that labor is immobile across sectors. Specifically, I assume 
that

$$
v\left(N_{X, t}, N_{Z, t}\right)=\left(1+\frac{1}{\eta}\right)^{-1}\left[\left(\phi\left(N_{Z, t}\right)^{\frac{\eta+\mu}{\eta}}+(1-\phi)\left(N_{X, t}\right)^{\frac{\eta+\mu}{\eta}}\right)^{\frac{\eta}{\eta+\mu}}\right]^{\left(1+\frac{1}{\eta}\right)},
$$

Here, $\eta$ is the Frisch labor supply elasticity and $\mu$ parameterizes labor mobility across sectors. If $\mu=0$, labor is perfectly mobile across sectors. If $\mu=1$, labor is completely immobile. Intermediate values imply partial labor mobility. ${ }^{24}$

Since greater labor mobility raises the elasticity of both sectors' supply curves, the sectoral multipliers increase slightly. Of course, more workers in one sector imply fewer in the other so the effect on the aggregate multiplier is small. In order to mimic severe slack in labor markets in recessions, I also compute multipliers for a calibration with greater labor supply elasticity $(\eta=2)$. This parameterization also implies more elastic sectoral supply curves but now additional hires in one sector do not draw labor away from the other. As a result all multipliers increase relative to the baseline.

An additional determinant of the short-run elasticity of supply curves are sticky prices. If prices are sticky, as in the baseline calibration, a fraction of firms must serve increased demand at fixed prices. When I assume that prices are flexible, the case $\theta_{X}=\theta_{Z}=0$, it is therefore unsurprising that multipliers fall. Naturally, this decline in multipliers relative to the baseline calibration is larger in the more price sensitive durable goods sectors.

Next, I consider an alternative Taylor rule in which the monetary authority responds stronger to both inflation and deviations of output from trend $\left(\phi_{\pi}=1.5, \phi_{Y}=0.5 / 4\right)$. As the open economy relative multiplier in Nakamura and Steinsson (2014), sectoral multipliers are less sensitive to alternative monetary policy rules than aggregate multipliers. Of course, aggregate multipliers fall when the monetary authority "leans against the wind" with increasing strength.

I next assume that the persistence of the government spending shock is higher and takes a value of 0.90 . This value corresponds to the persistence estimated in section $3.2 .3\left(0.9^{4 \cdot 7} \approx\right.$ 0.05). Longer lived shocks raise the multipliers for durable goods and reduces those for nondurables. Yet, the aggregate nondurables multiplier with a value of 0.70 remains more than twice the size of the durables multiplier which takes a value of 0.32 . For the empirical analysis in this paper, it is important that the industry-level multipliers also remain very different.

Finally, I explore the impact on fiscal multipliers when $D_{H}$ and $C$ are complements or substitutes (the last two lines of Table A1). The more complementary $D_{H}$ and $C$ are, the larger are the durable goods multipliers. However, the difference between nondurables and durable's multipliers remains large.

Across all calibrations, a good rule of thumb is that the aggregate multipliers lie between sectoral value added and gross output multipliers. In the simple model presented here, this rule suggests that the aggregate multiplier is between 0.1 and 0.35 for durable goods and around 0.75 for nondurables goods.

\footnotetext{
${ }^{24}$ This specification is taken from Barsky, House, and Kimball (2003).
} 
Table A1: Multipliers for alternative calibrations

\begin{tabular}{|c|c|c|c|c|c|c|}
\hline \multirow{2}{*}{$\begin{array}{l}\text { Small sector } \\
\text { Calibration }\end{array}$} & \multicolumn{3}{|c|}{$\begin{array}{l}15 \text { year service life, } \delta_{D}=0.017 \\
\text { Sectoral multiplier }\end{array}$} & \multicolumn{3}{|c|}{$\begin{array}{l}\text { Nondurable } \delta_{D}=1 \\
\text { Sectoral multiplier }\end{array}$} \\
\hline & $\begin{array}{l}\text { Gross } \\
\text { output }\end{array}$ & $\begin{array}{l}\text { Value } \\
\text { added }\end{array}$ & $\begin{array}{l}\text { Aggregate } \\
\text { multiplier }\end{array}$ & $\begin{array}{l}\text { Gross } \\
\text { output }\end{array}$ & $\begin{array}{l}\text { Value } \\
\text { added }\end{array}$ & $\begin{array}{l}\text { Aggregate } \\
\text { multiplier }\end{array}$ \\
\hline $\begin{array}{l}\text { Baseline } \\
\text { (baseline calibration) }\end{array}$ & 0.22 & 0.08 & 0.21 & 0.88 & 0.30 & 0.76 \\
\hline $\begin{array}{l}\text { High adjustment costs } \\
\zeta_{K}=100\end{array}$ & 0.22 & 0.08 & 0.22 & 0.88 & 0.30 & 0.83 \\
\hline $\begin{array}{l}\text { Low adjustment costs } \\
\zeta_{K}=1\end{array}$ & 0.20 & 0.08 & 0.18 & 0.88 & 0.32 & 0.43 \\
\hline $\begin{array}{l}\text { High labor mobility } \\
\mu=0.5\end{array}$ & 0.25 & 0.10 & 0.23 & 0.90 & 0.35 & 0.75 \\
\hline $\begin{array}{l}\text { High labor supply elasti } \\
\quad \eta=2\end{array}$ & 0.25 & 0.10 & 0.26 & 0.90 & 0.35 & 0.85 \\
\hline $\begin{array}{c}\text { Flexible prices } \\
\theta_{X}=\theta_{Z}=0\end{array}$ & 0.10 & 0.04 & 0.13 & 0.75 & 0.26 & 0.60 \\
\hline $\begin{array}{c}\text { More aggressive Taylor } \\
\phi_{\pi}=1.5, \phi_{Y}=0.5 / 4\end{array}$ & 0.22 & 0.08 & 0.20 & 0.87 & 0.30 & 0.63 \\
\hline $\begin{array}{l}\text { Greater shock persistenc } \\
\varrho_{X}=0.90\end{array}$ & 0.34 & 0.12 & 0.32 & 0.86 & 0.30 & 0.70 \\
\hline $\begin{array}{l}D_{H} \text { and } C \text { complements } \\
\rho=0.5\end{array}$ & 0.33 & 0.11 & 0.29 & 0.93 & 0.32 & 0.76 \\
\hline $\begin{array}{l}D_{H} \text { and } C \text { substitutes } \\
\quad \rho=2\end{array}$ & 0.13 & 0.05 & 0.15 & 0.79 & 0.27 & 0.75 \\
\hline
\end{tabular}

Notes: The table reports the multipliers at a time horizon of one year after the shock as generated by the model. 


\section{A.4 Additional impulse response functions}

Figure A1: Impulse response functions for a government spending shock
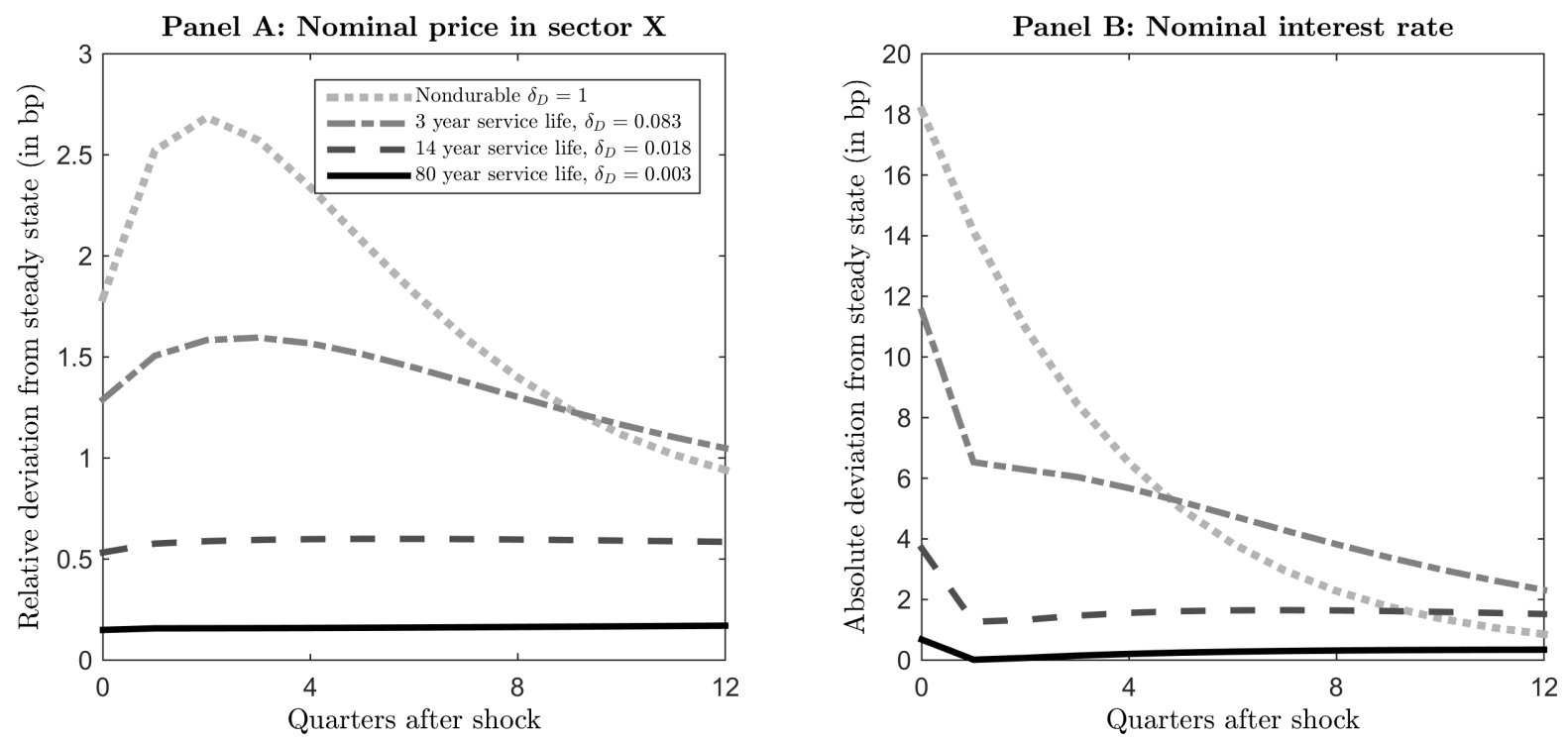

Notes: The figure plots impulse response functions for various calibrations. The impulse is a 100 basis point increase of government spending in sector $X$ relative to its steady state value. 


\section{B Appendix for aggregate empirical analysis}

\section{B.1 Data used in aggregate analysis}

The data are annual and come from the Bureau of Economic Analysis. GDP, the consumption series and investment in current dollars are taken from Table 1.1.5 and the corresponding price indexes are taken from Table 1.1.4. For $G_{X, t}$ I use national defense gross investment, and for $G_{C, t}$ I use national defense consumption expenditures. These series in current dollars are obtained from Table 3.9.5 and the price indexes from Table 3.9.4. Note that consumption expenditures include consumption of fixed capital. Additionally, roughly 5 to 10 percent of defense consumption expenditures are purchases of durable goods which cannot be separated out until 1972 because the Bureau of Economic Analysis begins to report a detailed breakdown of military spending only in 1972, Table 3.11.5. Hence, a small component of durable goods spending remains in the series $G_{C, t}$. Valerie Ramey's news series can be downloaded from her website (http://econweb.ucsd.edu/ vramey/research.html\#data). I obtain the trend of GDP $Y_{t}^{T}$ using an HP-filter with a smoothing parameter of 6.25 as recommended by Ravn and Uhlig (2002).

\section{B.2 Additional evidence from national accounts data}

From 1972 onwards, the BEA provides a more detailed breakdown of military spending in Table 3.11.5. This table contains time series of defense spending separately for services, nondurable goods, durable goods, equipment, and structures, among others. ${ }^{25} \mathrm{I}$ can use this data to test whether spending on these five categories leads to crowding out in the corresponding spending category for the private sector. To do so, I group services and nondurable goods together into a nondurables group, denoted $C$, and durable goods, equipment and structures into a durables group $X$. The data are now quarterly.

Let $Y_{P, i, t}$ denote private sector spending on category $i$. I estimate the specification

$$
\frac{Y_{P, i, t}-Y_{P, i, t-1}}{Y_{P, i, t-4}^{T}}=\sum_{s=1}^{4} \gamma_{X, s} \frac{G_{X, i, t-s+1}-G_{X, i, t-s}}{Y_{P, i, t-4}^{T}}+\sum_{s=1}^{4} \gamma_{C, s} \frac{G_{C, i, t-s+1}-G_{C, i, t-s}}{Y_{P, i, t-4}^{T}}+\delta_{t}+\zeta_{i}+\varepsilon_{i, t} .
$$

This empirical model is closely related to equation (19), but adjusted for quarterly data. Instead of Ramey's news variable, I now include a time fixed effect, $\delta_{t}$, which also soaks up the common component of other shocks such as monetary and tax policy. $\zeta_{i}$ is a fixed effect for each spending category. $G_{X, i, t}\left(G_{C, i, t}\right)$ denotes defense spending on category $i$ interacted with a dummy variable that takes the value one if and only if industry $i$ belongs to the durables group (the nondurables group). The multipliers are simply $\sum_{s=1}^{4} \gamma_{j, s}, j=C, X$.

Table B1 shows the results. In the baseline specification, column (1), the point estimate is -1.12 , suggesting that one dollar of spending in a durables category (durable goods, equip-

\footnotetext{
${ }^{25}$ The deflators are in Table 3.11.4.
} 
Table B1: Estimates from disaggregated national accounts data

\begin{tabular}{lccc}
\hline \hline Specification & $(1)$ & $(2)$ & $(3)$ \\
\hline Durable goods multiplier & -1.12 & -1.04 & -1.17 \\
& $(0.46)$ & $(0.47)$ & $(0.47)$ \\
Nondurable goods multiplier & 3.99 & 4.34 & 4.32 \\
& $(2.88)$ & $(2.86)$ & $(2.94)$ \\
Controls in addition to & none & interest rate & $\begin{array}{c}\text { Ramey news variable } \\
\text { interacted with } \\
\text { those in equation (A18) }\end{array}$ \\
& & $\begin{array}{c}\text { category dummy } \\
\text { category dummy }\end{array}$ & \\
\hline Observations & 845 & 845 & 845 \\
\hline Note: Standard errors in parentheses. & & &
\end{tabular}

ment, and structures) crowds out 1.12 dollars of private sector spending. The estimate is significantly different from zero at the 5 percent level. In contrast, the estimate for nondurable goods is positive and insignificantly different from zero. Unfortunately, the standard errors are fairly large.

In columns (2) and (3) of the table I report two estimates from specifications that include additional control variables. Column (2) reports the estimates when I include the real interest rate interacted with a category dummy. This control variable would allow monetary policy to affect the spending categories differently. The results in column (3) are obtained when I additionally control for Ramey's news variable interacted with category dummies. As can be seen from the table, the results are not sensitive to the inclusion of these additional controls. Although I do not report the estimates here, the findings are also robust to the inclusion of additional lags in specification (A18) so that the time horizon over which the multipliers are computed is greater than four quarters. 


\section{Appendix for industry-level empirical analysis}

\section{C.1 Industry-level data}

\section{C.1.1 Original data sources for sectoral analysis}

The NBER-CES manufacturing database can be downloaded from http://www.nber.org/ nberces/. This page also provides summary statistics of the dataset and a documentation. As noted in the text, a detailed description of the database is provided by Bartelsman and Gray (1996) and Becker, Gray, and Marvakov (2013).

The military prime contract files were downloaded from the U.S. National Archives, https://research.archives.gov/. After entering the website, search for the key words "military prime contracts" and "defense contract action data system". There is a separate set of files, i.e. the dataset and documentation, for each fiscal year from 1966 to 2003 . There is also a separate file for the 3-month period between the old and the new fiscal year in 1975.

The remaining data on military spending were obtained from www. usaspending.gov. More precisely, the data can be downloaded from/https://www. usaspending.gov/DownloadCenter/ Pages/DataDownload.aspx for the years from 2000 onwards. When downloading the data be sure to select "prime award" as type of data and "contracts" as spending type. The agency is the Department of Defense.

\section{C.1.2 Product Service Codes and Federal Supply Codes}

U.S. military procurement is categorized according to Product Service Codes (PSCs) and Federal Supply Codes (FSCs). Several examples are given in table C1. Individual categories can be looked up here: http://support . outreachsystems .com/resources/tables/ pscs/. A summary of all FSC and PSC codes as used after 1979 is available here: https: //www.fpds.gov/downloads/psc_data_0ct012011.xls. Both websites were last accessed on $06 / 16 / 2015$.

Table C1: Selected examples of PSC and FSC codes

\begin{tabular}{ll}
\hline \hline PSC/FSC & Description \\
\hline 1010 & Guns, over 30mm up to 75mm \\
1560 & Airframe structural components \\
1615 & Helicopter rotor blades, drive mechanisms and components \\
3820 & Mining, rock drilling, earth boring, and related equipment \\
AR32 & R\&D-Space: Flight (applied research/exploratory development) \\
M1GC & Operation of fuel storage buildings \\
R702 & Data collection services \\
& \\
\hline
\end{tabular}




\section{C.1.3 Concordance between FSC/PSC and SIC codes}

The military prime contract files contain both FSC/PSC codes and 4-digit SIC codes for the period from 1989 to 2000. I use these 12 years to construct a concordance and then apply the concordance to spending on FSC/PSC categories which are available over the entire sample from 1979 to 2009.

The concordance is a matrix that describes for each FSC and PSC code what fraction of a dollar spend on the FSC/PSC code is purchased from each SIC industry. For instance, if one dollar is spent on the FSC code 1010 (Guns, over 30mm up to $75 \mathrm{~mm}$ ) about 45 cents are purchased from SIC industry 3484 (Small Arms). The next most important SIC industry is 3489 (Ordnance and Accessories, NEC) with 25 cents. Table C2 provides a summary of all SIC industries that receive more than 1 cent when one dollar is spent on FSC code 1010. A second example is given in Table C3 for the FSC code 1560 (Airframe Structural Components).

Table C2: Spending shares for FSC code 1010 (Guns, over 30mm up to 75mm)

\begin{tabular}{llc}
\hline \hline SIC code & Description & Spending share \\
\hline & & \\
3484 & Small Arms & 0.448 \\
3489 & Ordnance and Accessories, NEC & 0.254 \\
3499 & Fabricated Metal Products, NEC & 0.166 \\
8711 & Engineering Services & 0.086 \\
3728 & Aircraft Parts and Auxiliary Equipment, NEC & 0.021 \\
& & \\
\hline
\end{tabular}

Table C3: Spending shares for FSC code 1560 (Airframe Structural Components)

\begin{tabular}{llc}
\hline \hline SIC code & Description & Spending share \\
\hline & & \\
3728 & Aircraft Parts and Auxiliary Equipment, NEC & 0.815 \\
3721 & Aircraft & 0.069 \\
8711 & Engineering Services & 0.033 \\
3724 & Aircraft Engines and Engine Parts & 0.023 \\
8731 & Commercial Physical and Biological Research & 0.022 \\
\end{tabular}




\section{C.2 Sample description}

Table C4: Industries and basic summary statistics

\begin{tabular}{|c|c|c|c|}
\hline $\begin{array}{l}\text { SIC } \\
\text { code }\end{array}$ & Durable & $\begin{array}{c}\text { Avg. def. } \\
\text { spending } \\
\text { share (in \%) }\end{array}$ & Description \\
\hline 2032 & no & 1.8 & Canned Specialties \\
\hline 2086 & no & 2.0 & Bottled and Canned Soft Drinks and Carbonated Water \\
\hline 2097 & no & 1.0 & Manufactured Ice \\
\hline 2099 & no & 1.2 & Food Preparations, NEC \\
\hline 2231 & no & 5.7 & Broadwoven Fabric Mills, Wool \\
\hline 2254 & no & 3.1 & Knit Underwear and Nightwear Mills \\
\hline 2298 & no & 2.2 & Cordage and Twine \\
\hline 2299 & no & 2.7 & Textile Goods, NEC \\
\hline 2311 & no & 9.0 & Mens and Boys Suits, Coats, and Overcoats \\
\hline 2321 & no & 1.9 & Mens and Boys Shirts, Except Work Shirts \\
\hline 2322 & no & 10.9 & Mens and Boys Underwear and Nightwear \\
\hline 2325 & no & 7.3 & Mens and Boys Separate Trousers and Slacks \\
\hline 2326 & no & 3.8 & Mens and Boys Work Clothing \\
\hline 2329 & no & 6.8 & Mens and Boys Clothing, NEC \\
\hline 2353 & no & 6.1 & Hats, Caps, and Millinery \\
\hline 2371 & no & 2.8 & Fur Goods \\
\hline 2381 & no & 17.6 & Dress and Work Gloves, Except Knit and All-Leather \\
\hline 2385 & no & 32.2 & Waterproof Outerwear \\
\hline 2387 & no & 1.5 & Apparel Belts \\
\hline 2389 & no & 2.6 & Apparel and Accessories, NEC \\
\hline 2393 & no & 5.9 & Textile Bags \\
\hline 2394 & no & 8.7 & Canvas and Related Products \\
\hline 2399 & no & 8.7 & Fabricated Textile Products, NEC \\
\hline 2519 & yes & 1.1 & Household Furniture, NEC \\
\hline 2521 & yes & 2.4 & Wood Office Furniture \\
\hline 2522 & yes & 2.0 & Office Furniture, Except Wood \\
\hline 2599 & yes & 1.5 & Furniture and Fixtures, NEC \\
\hline 2741 & no & 2.1 & Miscellaneous Publishing \\
\hline 2813 & no & 2.4 & Industrial Gases \\
\hline 2836 & no & 1.4 & Biological Products, Except Diagnostic Substances \\
\hline 2892 & no & 22.2 & Explosives \\
\hline 2911 & no & 1.6 & Petroleum Refining \\
\hline 2992 & no & 1.7 & Lubricating Oils and Greases \\
\hline 3021 & no & 2.5 & Rubber and Plastics Footwear \\
\hline 3053 & no & 1.3 & Gaskets, Packing, and Sealing Devices \\
\hline 3069 & no & 1.4 & Fabricated Rubber Products, NEC \\
\hline 3143 & no & 6.9 & Mens Footwear, Except Athletic \\
\hline 3149 & no & 5.5 & Footwear, Except Rubber, NEC \\
\hline 3151 & no & 12.1 & Leather Gloves and Mittens \\
\hline 3261 & yes & 2.3 & $\begin{array}{l}\text { Vitreous China Plumbing Fixtures and China and } \\
\text { Earthenware Fittings and Bathroom Accessories }\end{array}$ \\
\hline 3295 & yes & 5.3 & Minerals and Earths, Ground or Otherwise Treated \\
\hline 3299 & yes & 1.1 & Nonmetallic Mineral Products, NEC \\
\hline
\end{tabular}

Continued on next page 
Table C4 - Continued from previous page

\begin{tabular}{|c|c|c|c|}
\hline $\begin{array}{l}\text { SIC } \\
\text { code }\end{array}$ & Durable & $\begin{array}{c}\text { Avg. def. } \\
\text { spending } \\
\text { share (in \%) }\end{array}$ & Description \\
\hline 3315 & yes & 1.1 & Steel Wiredrawing and Steel Nails and Spikes \\
\hline 3399 & yes & 1.4 & Primary Metal Products, NEC \\
\hline 3412 & yes & 1.6 & Metal Shipping Barrels, Drums, Kegs, and Pails \\
\hline 3429 & yes & 6.2 & Hardware, NEC \\
\hline 3443 & yes & 6.1 & Fabricated Plate Work \\
\hline 3448 & yes & 1.9 & Prefabricated Metal Buildings and Components \\
\hline 3452 & yes & 1.6 & Bolts, Nuts, Screws, Rivets, and Washers \\
\hline 3484 & yes & 16.3 & Small Arms \\
\hline 3494 & yes & 6.4 & Valves and Pipe Fittings, NEC \\
\hline 3499 & yes & 4.3 & Fabricated Metal Products, NEC \\
\hline 3511 & yes & 8.6 & $\begin{array}{c}\text { Steam, Gas, and Hydraulic Turbines, and } \\
\text { Turbine Generator Set Units }\end{array}$ \\
\hline 3519 & yes & 1.6 & Internal Combustion Engines, NEC \\
\hline 3536 & yes & 3.8 & Overhead Traveling Cranes, Hoists, and Monorail Systems \\
\hline 3537 & yes & 5.7 & Industrial Trucks, Tractors, Trailers, and Stackers \\
\hline 3541 & yes & 1.6 & Machine Tools, Metal Cutting Types \\
\hline 3542 & yes & 1.2 & Machine Tools, Metal Forming Type \\
\hline 3559 & yes & 4.8 & Special Industry Machinery, NEC \\
\hline 3561 & yes & 1.6 & Pumps and Pumping Equipment \\
\hline 3562 & yes & 1.7 & Ball and Roller Bearings \\
\hline 3564 & yes & 1.2 & $\begin{array}{l}\text { Industrial and Commercial Fans and Blowers and } \\
\text { Air Purification Equipment }\end{array}$ \\
\hline 3566 & yes & 6.5 & Speed Changers, Industrial High-Speed Drives, and Gears \\
\hline 3568 & yes & 2.9 & Mechanical Power Transmission Equipment, NEC \\
\hline 3569 & yes & 2.7 & General Industrial Machinery and Equipment, NEC \\
\hline 3571 & yes & 4.2 & Electronic Computers \\
\hline 3572 & yes & 1.3 & Computer Storage Devices \\
\hline 3575 & yes & 11.2 & Computer Terminals \\
\hline 3577 & yes & 3.1 & Computer Peripheral Equipment, NEC \\
\hline 3578 & yes & 1.1 & Calculating and Accounting Machinery, Except Electronic Computers \\
\hline 3579 & yes & 2.1 & Office Machines, NEC \\
\hline 3582 & yes & 1.5 & Commercial Laundry, Drycleaning, and Pressing Machines \\
\hline 3586 & yes & 1.3 & Measuring and Dispensing Pumps \\
\hline 3589 & yes & 1.2 & Service Industry Machinery, NEC \\
\hline 3612 & yes & 3.7 & Power, Distribution, and Specialty Transformers \\
\hline 3613 & yes & 1.0 & Switchgear and Switchboard Apparatus \\
\hline 3621 & yes & 3.5 & Motors and Generators \\
\hline 3629 & yes & 1.8 & Electrical Industrial Apparatus, NEC \\
\hline 3643 & yes & 1.6 & Current-Carrying Wiring Devices \\
\hline 3644 & yes & 1.7 & Noncurrent-Carrying Wiring Devices \\
\hline 3647 & yes & 1.7 & Vehicular Lighting Equipment \\
\hline 3648 & yes & 1.3 & Lighting Equipment, NEC \\
\hline 3661 & yes & 2.0 & Telephone and Telegraph Apparatus \\
\hline 3663 & yes & 11.6 & Radio and Television Broadcasting and Communications Equipment \\
\hline 3671 & yes & 23.1 & Electron Tubes \\
\hline 3672 & yes & 2.7 & Printed Circuit Boards \\
\hline
\end{tabular}


Table C4 - Continued from previous page

\begin{tabular}{|c|c|c|c|}
\hline $\begin{array}{l}\text { SIC } \\
\text { code }\end{array}$ & Durable & $\begin{array}{c}\text { Avg. def. } \\
\text { spending } \\
\text { share (in \%) }\end{array}$ & Description \\
\hline 3676 & yes & 3.0 & Electronic Resistors \\
\hline 3677 & yes & 1.5 & Electronic Coils, Transformers, and Other Inductors \\
\hline 3679 & yes & 6.6 & Electronic Components, NEC \\
\hline 3691 & yes & 1.5 & Storage Batteries \\
\hline 3692 & yes & 4.4 & Primary Batteries, Dry and Wet \\
\hline 3695 & yes & 2.8 & Magnetic and Optical Recording Media \\
\hline 3699 & yes & 10.8 & Electrical Machinery, Equipment, and Supplies, NEC \\
\hline 3715 & yes & 4.3 & Truck Trailers \\
\hline 3721 & yes & 29.4 & Aircraft \\
\hline 3724 & yes & 27.6 & Aircraft Engines and Engine Parts \\
\hline 3732 & yes & 1.2 & Boat Building and Repairing \\
\hline 3764 & yes & 12.5 & $\begin{array}{c}\text { Guided Missile and Space Vehicle Propulsion Units } \\
\text { and Propulsion Unit Parts }\end{array}$ \\
\hline 3799 & yes & 1.5 & Transportation Equipment, NEC \\
\hline 3812 & yes & 15.1 & $\begin{array}{l}\text { Search, Detection, Navigation, Guidance, Aeronautical, } \\
\text { and Nautical Systems and Instruments }\end{array}$ \\
\hline 3821 & yes & 1.9 & Laboratory Apparatus and Furniture \\
\hline 3823 & yes & 1.2 & $\begin{array}{c}\text { Industrial Instruments for Measurement, Display, and Control of } \\
\text { Process Variables; and Related Products }\end{array}$ \\
\hline 3825 & yes & 4.2 & $\begin{array}{l}\text { Instruments for Measuring and Testing of Electricity } \\
\text { and Electrical Signals }\end{array}$ \\
\hline 3826 & yes & 1.6 & Laboratory Analytical Instruments \\
\hline 3827 & yes & 10.0 & Optical Instruments and Lenses \\
\hline 3829 & yes & 7.2 & Measuring and Controlling Devices, NEC \\
\hline 3841 & yes & 1.3 & Surgical and Medical Instruments and Apparatus \\
\hline 3842 & yes & 2.1 & Orthopedic, Prosthetic, and Surgical Appliances and Supplies \\
\hline 3843 & yes & 2.1 & Dental Equipment and Supplies \\
\hline 3844 & yes & 1.3 & X-Ray Apparatus and Tubes and Related Irradiation Apparatus \\
\hline 3999 & yes & 2.1 & Manufacturing Industries, NEC \\
\hline
\end{tabular}




\section{C.3 Additional results}

Figure C2: Spending response for durable and nondurable goods

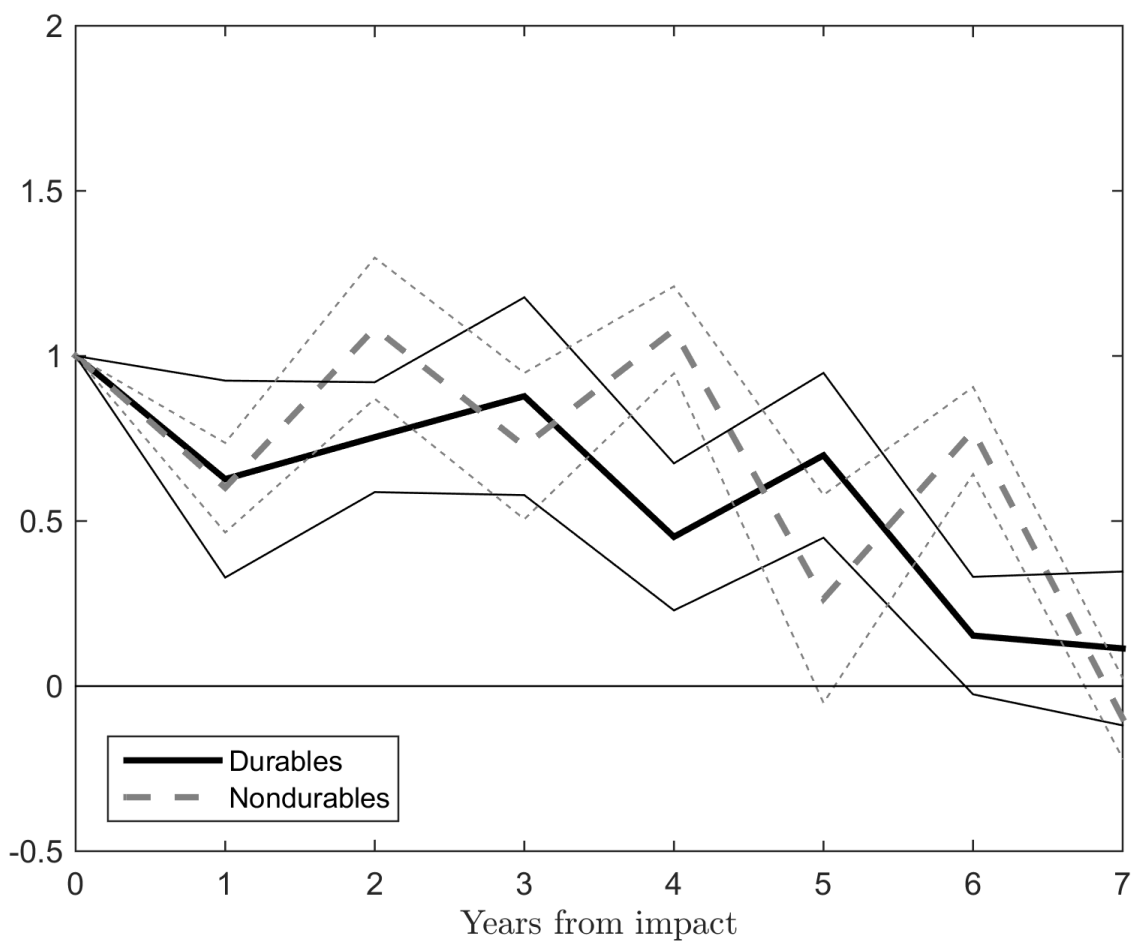

Notes: The figure plots impulse response functions of military spending for the baseline sample estimated using specification (20). Shaded regions mark 80 percent confidence bands based on standard errors that are clustered at the industry level. 


\section{C.4 Robustness}

Table C5: Sectoral multipliers when controlling for Ramey's news variable

\begin{tabular}{|c|c|c|c|c|c|c|}
\hline \multirow[b]{2}{*}{ Years after shock } & \multicolumn{3}{|c|}{ 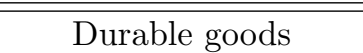 } & \multicolumn{3}{|c|}{ "Nondurable goods } \\
\hline & 1 & 2 & 3 & 1 & 2 & 3 \\
\hline Gross output & 0.26 & 0.23 & 0.73 & 2.83 & 2.49 & 2.83 \\
\hline Value added & 0.44 & 0.38 & 0.71 & 0.97 & 0.83 & 1.13 \\
\hline Cost of materials & 0.05 & 0.01 & 0.10 & 1.82 & 1.31 & 1.49 \\
\hline Energy expenditures & 0.010 & 0.006 & 0.009 & 0.064 & 0.066 & 0.047 \\
\hline $\begin{array}{l}\text { Employment } \\
\text { (employees per year per } \$ 1 \mathrm{~m})\end{array}$ & 2.04 & 3.47 & 7.42 & 17.73 & 18.16 & 21.78 \\
\hline
\end{tabular}

Notes: See notes of Table 4. The estimates are based on specification (20), augmented by Ramey's news variable interacted with industry indicators.

Table C6: Sectoral multipliers when allowing for industry-specific effects of monetary policy

\begin{tabular}{|c|c|c|c|c|c|c|}
\hline \multirow[b]{2}{*}{ Years after shock } & \multicolumn{3}{|c|}{ Durable goods } & \multicolumn{3}{|c|}{ "Nondurable goods } \\
\hline & 1 & 2 & 3 & 1 & 2 & 3 \\
\hline Gross output & 0.34 & 0.21 & 0.45 & 2.58 & 2.67 & 3.24 \\
\hline Value added & 0.40 & 0.35 & 0.55 & 0.97 & 0.94 & 1.29 \\
\hline Cost of materials & 0.00 & -0.10 & -0.08 & 1.61 & 1.52 & 1.92 \\
\hline Energy expenditures & 0.008 & 0.005 & 0.007 & 0.056 & 0.063 & 0.050 \\
\hline $\begin{array}{l}\text { Employment } \\
\text { (employees per year per } \$ 1 \mathrm{~m})\end{array}$ & 2.29 & 3.29 & 5.75 & 15.56 & 15.25 & 17.66 \\
\hline
\end{tabular}

Notes: See notes of Table 4. The estimates are based on specification (20), augmented by interactions of the real interest rate with industry indicators. 
Table C7: Sectoral multipliers for a smoothing parameter of 400

\begin{tabular}{|c|c|c|c|c|c|c|}
\hline \multirow[b]{2}{*}{ Years after shock } & \multicolumn{3}{|c|}{ Durable goods } & \multicolumn{3}{|c|}{ Nondurable goods } \\
\hline & 1 & 2 & 3 & 1 & 2 & 3 \\
\hline Gross output & -0.05 & -0.05 & 0.19 & 2.24 & 2.27 & 2.86 \\
\hline Value added & 0.17 & 0.19 & 0.40 & 0.81 & 0.76 & 1.15 \\
\hline Cost of materials & -0.14 & -0.20 & -0.21 & 1.15 & 1.04 & 1.45 \\
\hline Energy expenditures & 0.005 & 0.003 & 0.004 & 0.066 & 0.073 & 0.060 \\
\hline $\begin{array}{l}\text { Employment } \\
\text { (employees per year per } \$ 1 \mathrm{~m})\end{array}$ & 1.39 & 3.23 & 6.37 & 15.96 & 15.32 & 18.45 \\
\hline
\end{tabular}

Notes: See notes of Table 4. The results in this table are obtained when the trends for all variables are extracted with a smoothing parameter of 400 .

Table C8: Sectoral multipliers for a smoothing parameter of 6000

\begin{tabular}{|c|c|c|c|c|c|c|}
\hline \multirow[b]{2}{*}{ Years after shock } & \multicolumn{3}{|c|}{ Durable goods } & \multicolumn{3}{|c|}{ Nondurable goods } \\
\hline & 1 & 2 & 3 & 1 & 2 & 3 \\
\hline Gross output & 0.52 & 0.50 & 0.78 & 2.82 & 2.94 & 3.38 \\
\hline Value added & 0.52 & 0.51 & 0.73 & 1.07 & 1.07 & 1.35 \\
\hline Cost of materials & 0.11 & 0.08 & 0.13 & 1.88 & 1.86 & 2.18 \\
\hline Energy expenditures & 0.010 & 0.007 & 0.009 & 0.050 & 0.051 & 0.038 \\
\hline $\begin{array}{l}\text { Employment } \\
\text { (employees per year per } \$ 1 \mathrm{~m})\end{array}$ & 2.25 & 3.34 & 5.65 & 15.19 & 14.77 & 16.40 \\
\hline
\end{tabular}

Notes: See notes of Table 4. The results in this table are obtained when the trends for all variables are extracted with a smoothing parameter of 6000 . 
Table C9: Sectoral multipliers estimated from 3-digit SIC industries

\begin{tabular}{|c|c|c|c|}
\hline \multirow[b]{2}{*}{ Years after shock } & \multicolumn{3}{|c|}{ Durable goods } \\
\hline & 1 & 2 & 3 \\
\hline Gross output & -0.24 & -0.23 & 0.02 \\
\hline Value added & -0.12 & -0.06 & 0.01 \\
\hline Cost of materials & 0.17 & 0.17 & 0.31 \\
\hline Energy expenditures & 0.002 & 0.002 & 0.003 \\
\hline $\begin{array}{l}\text { Employment } \\
\text { (employees per year per } \$ 1 \mathrm{~m})\end{array}$ & -2.67 & -0.95 & 0.20 \\
\hline
\end{tabular}

Notes: See notes of Table 4 . 


\section{C.5 Impulse response functions of prices}

I estimate the specification

$$
\begin{aligned}
\frac{P_{i, t+h}-P_{i, t-1}^{T}}{P_{i, t-1}^{T}}= & \alpha_{h} \frac{G_{i, t}-G_{i, t-1}^{T}}{V A_{i, t-1}^{T}}+\sum_{k=1}^{2} \beta_{h}^{k} \frac{P_{i, t-k}-P_{i, t-k-1}^{T}}{P_{i, t-k-1}^{T}} \\
& +\sum_{k=1}^{2} \gamma_{h}^{k} \frac{G_{i, t-k}-G_{i, t-k-1}^{T}}{V A_{i, t-k-1}^{T}}+\delta_{i, h}+\zeta_{t, h}+\varepsilon_{i, t+h},
\end{aligned}
$$

where $P_{i, t}$ denotes the industry's consumption wage, price, or product wage. The coefficients $\left\{\alpha_{h}\right\}_{h=0}^{4}$ are now akin to semi-elasticities and interpreted as follows. When the difference between government spending and its trend, normalized by the sector's value added, rises by one, the government engages, on average, in further spending in subsequent periods as shown in Panel A of Figure 3. This spending path is associated with a price response, expressed as a percentage deviation from trend, given by $\left\{\alpha_{h}\right\}_{h=0}^{4}$. As before, the spending variables on the right-hand side of equation (A19) is instrumented with (21) and its two lags. The first stage Angrist-Pischke F-statistics are essentially identical to those reported in Table 3.

Figure C3 displays the results. All prices, consumption wages (Panel A), product prices (Panel B), and product wages (Panel C) respond little in response to a fiscal shock. These effects are at odds with standard theory but not uncommon in the fiscal policy literature (see e.g. Nakamura and Steinsson, 2014).

Figure C3: Impulse response functions of prices

Panel A: Consumption wages

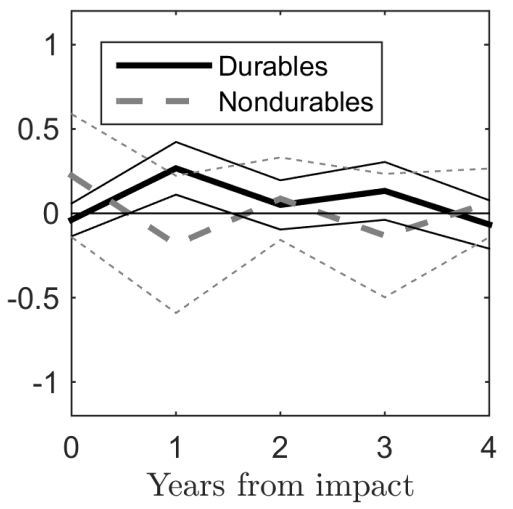

Panel B: Prices

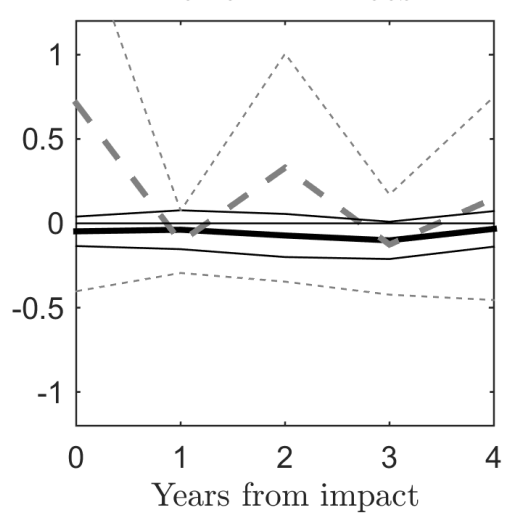

Panel C: Product wages

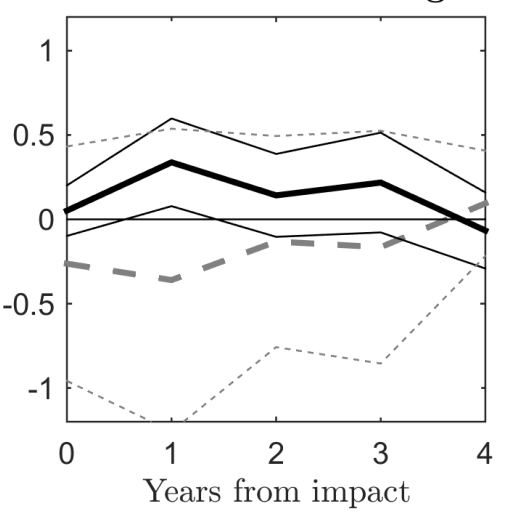

Notes: The figure plots impulse response functions estimated from specification (A19) for the baseline sample as described in the text. The shock is a unit increase of government spending above trend, normalized by the sector's value added. Shaded regions mark 80 percent confidence bands based on standard errors that are clustered at the industry level. 
There are a number of candidate explanations for the weak prices responses. First, due to their high price sensitivity, fluctuations of durable goods prices should generally be small and hard to detect. ${ }^{26}$ Second, there may be composition effects. The military likely purchases a different basket of goods from a particular sector than the private sector. If the basket purchased by the military has a lower price than that purchased by the private sector, then no price response may be registred. Another possible explanation is that the government purchases goods in bulk and receives greater discounts than the private sector. Given that many nondurable goods sectors in the sample produce food, this explanation seems plausible. Yet, the weak responses of prices after fiscal shocks remain puzzling.

\footnotetext{
${ }^{26}$ See, for example, House and Shapiro (2008).
} 


\section{C.6 State dependence}

Table C10: First stages of the state-dependent specification

\begin{tabular}{|c|c|c|c|c|c|c|c|}
\hline First stage dep. Variable & & Horizon $h$ & 0 & 1 & 2 & 3 & 4 \\
\hline \multirow{3}{*}{$F_{i, t-1} \frac{G_{i, t}-G_{i, t-1}^{T}}{V A_{i, t-1}^{T}}$} & AP F-statistic & & 132.8 & 116.1 & 125.3 & 115.8 & 38.2 \\
\hline & p-value & & 0.00 & 0.00 & 0.00 & 0.00 & 0.00 \\
\hline & R-squared & & 0.44 & 0.45 & 0.49 & 0.50 & 0.51 \\
\hline \multirow{3}{*}{$\left(1-F_{i, t-1}\right) \frac{G_{i, t}-G_{i, t-1}^{T}}{V A_{i, t-1}^{T}}$} & AP F-statistic & & 93.0 & 143.7 & 257.62 & 237.6 & 168.7 \\
\hline & $\mathrm{p}$-value & & 0.00 & 0.00 & 0.00 & 0.00 & 0.00 \\
\hline & R-squared & & 0.43 & 0.54 & 0.57 & 0.58 & 0.59 \\
\hline \multirow{3}{*}{$F_{i, t-1} \frac{G_{i, t-1}-G_{i, t-2}^{T}}{V A_{i, t-2}^{T}}$} & AP F-statistic & & 95.9 & 92.2 & 80.1 & 47.1 & 18.2 \\
\hline & p-value & & 0.00 & 0.00 & 0.00 & 0.00 & 0.00 \\
\hline & R-squared & & 0.46 & 0.49 & 0.51 & 0.51 & 0.53 \\
\hline \multirow{3}{*}{$\left(1-F_{i, t-1}\right) \frac{G_{i, t-1}-G_{i, t-2}^{T}}{V A_{i, t-2}^{T}}$} & AP F-statistic & & 205.3 & 244.4 & 204.6 & 161.4 & 96.5 \\
\hline & $\mathrm{p}$-value & & 0.00 & 0.00 & 0.00 & 0.00 & 0.00 \\
\hline & R-squared & & 0.53 & 0.58 & 0.58 & 0.59 & 0.60 \\
\hline \multirow{3}{*}{$F_{i, t-1} \frac{G_{i, t-2}-G_{i, t-3}^{T}}{V A_{i, t-3}^{T}}$} & AP F-statistic & & 171.4 & 186.9 & 198.1 & 103.6 & 59.5 \\
\hline & $\mathrm{p}$-value & & 0.00 & 0.00 & 0.00 & 0.00 & 0.00 \\
\hline & R-squared & & 0.45 & 0.47 & 0.49 & 0.50 & 0.51 \\
\hline \multirow{3}{*}{$\left(1-F_{i, t-1}\right) \frac{G_{i, t-2}-G_{i, t-3}^{T}}{V A_{i, t-3}^{T}}$} & AP F-statistic & & 166.3 & 196.5 & 306.6 & 259.4 & 189.7 \\
\hline & $\mathrm{p}$-value & & 0.00 & 0.00 & 0.00 & 0.00 & 0.00 \\
\hline & R-squared & & 0.60 & 0.60 & 0.60 & 0.61 & 0.61 \\
\hline Observations & & & 2115 & 2039 & 1963 & 1887 & 1811 \\
\hline
\end{tabular}

Notes: The table shows the first stages of the 2SLS estimator of specification (22) when the dependent variable is value added. For all other dependent variables, the F-statistics are virtually identical. The instruments are (21) and its two lags, interacted with $F_{i, t-1}$ and $1-F_{i, t-1}$. AP F-statistic stands for Angrist-Pischke F-statistic and the subsequent lines show the associated p-values. 